\title{
Southern Ocean deep convection in global climate models: a driver for variability of subpolar gyres and Drake Passage transport on decadal time scales
}

Article

Published Version

Behrens, E., Rickard, G., Morgenstern, O., Martin, T., Osprey, A. and Joshi, M. (2016) Southern Ocean deep convection in global climate models: a driver for variability of subpolar gyres and Drake Passage transport on decadal time scales. Journal of Geophysical Research: Oceans, 121 (6). pp. 3905-3925. ISSN 2169-9291 doi: https://doi.org/10.1002/2015JC011286 Available at https://centaur.reading.ac.uk/69292/

It is advisable to refer to the publisher's version if you intend to cite from the work. See Guidance on citing.

To link to this article DOI: http://dx.doi.org/10.1002/2015JC011286

Publisher: American Geophysical Union

All outputs in CentAUR are protected by Intellectual Property Rights law, including copyright law. Copyright and IPR is retained by the creators or other copyright holders. Terms and conditions for use of this material are defined in the End User Agreement. 


\section{www.reading.ac.uk/centaur}

\section{CentAUR}

Central Archive at the University of Reading

Reading's research outputs online 


\section{Journal of Geophysical Research: Oceans}

\section{RESEARCH ARTICLE}

10.1002/2015JC011286

Key Points:

- Overly strong Southern Ocean open ocean convection is a common

feature in CMIP5 models

- Intermittent deep convection events stimulate decadal to multidecadal oceanic variability

- Freshwater triggered positive stratification anomalies often precede strong convection events

Supporting Information:

- Supporting Information S1

- Figure S1

- Figure S2

- Figure S3

Correspondence to:

E. Behrens,

erik.behrens@niwa.co.nz

\section{Citation:}

Behrens, E., G. Rickard, O. Morgenstern, T. Martin, A. Osprey, and M. Joshi (2016), Southern Ocean deep convection in global climate models: A driver for variability of subpolar gyres and Drake Passage transport on decadal timescales, J. Geophys. Res. Oceans, 121, 3905-3925, doi:10.1002/ 2015JC011286.

Received 31 AUG 2015 Accepted 6 MAY 2016 Accepted article online 10 MAY 2016 Published online 5 JUN 2016

\section{Southern Ocean deep convection in global climate models: A driver for variability of subpolar gyres and Drake Passage transport on decadal timescales}

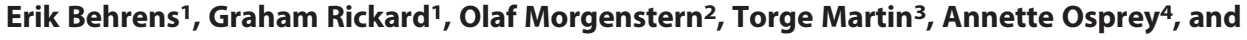 \\ Manoj Joshi5,6 \\ ${ }^{1}$ Marine Physics, National Institute of Water and Atmospheric Research, Wellington, New Zealand, ${ }^{2}$ Atmosphere and \\ Climate, National Institute of Water and Atmospheric Research, Wellington, New Zealand, ${ }^{3}$ Ocean Circulation and Climate \\ Dynamics, GEOMAR Helmholtz Centre for Ocean Research Kiel, Kiel, Germany, ${ }^{4}$ Department of Meteorology, University of \\ Reading, Reading, UK, ${ }^{5}$ Centre for Ocean and Atmospheric Sciences, University of East Anglia, Norwich, UK, ${ }^{6} \mathrm{Climatic}$ \\ Research Unit, University of East Anglia, Norwich, UK
}

\begin{abstract}
We investigate the individual and joint decadal variability of Southern Ocean state quantities, such as the strength of the Ross and Weddell Gyres, Drake Passage transport, and sea ice area, using the National Institute of Water and Atmospheric Research UK Chemistry and Aerosols (NIWAUKCA) model and CMIP5 models. Variability in these quantities is stimulated by strong deep reaching convective events in the Southern Ocean, which produce an Antarctic Bottom Water-like water mass and affect the large-scale meridional density structure in the Southern Ocean. An increase in the (near) surface stratification, due to freshwater forcing, can be a precondition for subsequent strong convection activity. The combination of enhanced-gyre driven sea ice and freshwater export, as well as ongoing subsurface heat accumulation, lead to a time lag between changes in oceanic freshwater and heat content. This causes an ongoing weakening of the stratification until sudden strong mixing events emerge and the heat is released to the atmosphere. We find that strong convection reduces sea ice cover, weakens the subpolar gyres, increases the meridional density gradient and subsequently results in a positive Drake Passage transport anomaly. Results of available CMIP5 models confirm that variability in sea ice, Drake Passage transport, and the Weddell Gyre strength is enhanced if models show strong open ocean convective events. Consistent relationships between convection, sea ice, Drake Passage transport, and Ross Gyre strength variability are evident in most models, whether or not they host open ocean convection.
\end{abstract}

\section{Introduction}

The Southern Ocean is a key component of the Earth's climate system and hosts the complex Antarctic Circumpolar Current (ACC). On the one hand, the ACC connects all the World's oceans and thus facilitates cross basin transport and redistribution of heat, freshwater, and nutrients [Rintoul and Naveira Garabato, 2013]. On the other hand, the strong zonal currents shield the Antarctic ice sheet from direct heating by warmer low-latitude water masses. Recent Southern Ocean-related research has focused on understanding physical mechanisms driving the climate variability, related feedbacks, and past and future changes [e.g., Böning et al., 2008; Meijers et al., 2012; Downes and Hogg, 2013; Purkey and Johnson, 2013; Meijers, 2014; Downes et al., 2015; Farneti et al., 2015]. Despite all these efforts, the Southern Ocean remains a sparsely sampled and highly challenging region to obtain observations (ARGO (http://www.argo.ucsd.edu/), WOCE (https://www.nodc.noaa.gov/woce/)).

The limitations in observational data strengthen the need for sophisticated numerical models to unravel physical mechanisms of climate variability in the Southern Ocean. Recent studies, in particular, have sought to understand the oceanic response to the poleward intensification of the Westerlies, [e.g., Farneti et al., 2010; Meredith et al., 2012] and to explain recent observed sea ice extent increase [Holland and Kwok, 2012; Bintanja et al., 2013; Goosse and Zunz, 2014]. Furthermore, much effort has been devoted to understand the reasons for recent warming and freshening of Antarctic Bottom Water (AABW) [Rintoul, 2007; Purkey and Johnson, 2013] and near-coastal oceanic changes affecting the melting of Antarctic ice shelves [Spence et al., 2014]. 
Oceanic model resolution has important effects on the representation of circulation and water mass properties in the Ross Sea and, thus, for the formation of AABW [Rickard et al., 2010]. In this respect, highresolution eddy resolving model simulations have improved our understanding of the complex interactions in the Southern Ocean between wind stress, mesoscale eddies, and the overturning circulation [Farneti et al., 2010]. Nonuniform trends in the observed eddy field [Hogg et al., 2013] confirm the complexity of the ACC response to zonal wind trends. Holland and Kwok [2012] have demonstrated that wind trends can provide a possible explanation for the observed positive trend in sea ice over the recent decades. However, it is still a challenge for global climate models to simulate those observed trends [Turner et al., 2013; Meijers, 2014] as not all feedbacks and processes are well-understood and/or resolved (e.g., AABW production) [Heuzé et al., 2013]. Nonetheless, the ensemble behavior of coupled models does provide some confidence in projected trends of winds, subpolar gyre transports and density structure [Meijers et al., 2012; Wang, 2013] in the ACC region.

A further challenge is the lack of understanding of internal and natural variability on decadal timescales and beyond in the Southern Ocean, making decadal to multidecadal climate predictions and attribution of contemporary trends even more difficult [e.g., Latif et al., 2013]. Open ocean convection is a potential driver for variability on those time scales but has been only observed once during the winters between 1974 and 1976 in the Weddell Sea region (the so-called Weddell Sea polynya) [Carsey, 1980]. As shown by de Lavergne et al. [2014], increased stratification under global warming will likely prevent its recurrence in the $21 \mathrm{st}$ century.

In Coupled Model Intercomparion Project 5 (CMIP5) simulations, the location and intensity of deep convection is strongly model-dependent [Heuzé et al., 2013; de Lavergne et al., 2014]. Martin et al. [2013] showed that convective events in the Kiel Climate Model can trigger variability on centennial time scales in the Southern Ocean and the North Atlantic. They also demonstrated that during nonconvective phases a strong increase in heat content is observed in the Weddell Sea, causing a slow weakening of subsurface stratification. After convection has depleted this heat reservoir during the convective phase, a coincident freshening promotes the shutdown of the convection. In addition, sea ice cover in those regions is reduced during convective periods which contributes to the large variability seen in CMIP5 simulations [Turner et al., 2013]. Stössel et al. [2014] found that freshwater from the Antarctic ice-sheet and icebergs could contribute to the shutdown of convective events or inhibit their occurrence in the first place as additional freshwater increased surface stratification. Whether open ocean deep convection is regarded as "spurious," because of the difficulties in capturing it correctly in numerical models [Heuzé et al., 2015], or as an integral part of natural variability [Latif et al., 2013], it is clearly necessary to better understand the processes and feedbacks involved in ocean convection and resulting implications for the Southern Ocean.

In this paper, we provide additional insight on processes involved in triggering open ocean convection in the Southern Ocean and present new results for its impact on future decadal variability in subpolar gyre and Drake Passage transport strength transport strength. Our results corroborate the findings of Martin et al. [2013] but also highlight the importance of a slight phase shift of a few years between freshwater and heat content anomalies south of $67^{\circ} \mathrm{S}$, caused by an enhanced gyre-driven northward sea ice export and an ongoing subsurface heat accumulation. Our analysis of the NIWA-UKCA ensemble shows that convection stimulates variability in subpolar gyre strength, Drake Passage transport, and sea ice area. It also elucidates covariability and relationships between Southern Ocean state variables. We then repeat our analysis using available CMIP5 models in order to quantify the robustness of the NIWA-UKCA findings. A comparison with satellite observations suggest that the relationships between deep convection, subpolar gyre strength, and sea ice variability in the model results are not supported by observations.

The paper is structured as follows: In section 2, we describe the model and observational data and methods used in this study. Section 3 is divided into results of the NIWA-UKCA ensemble (section 3.1), CMIP5 (section 3.2), and observations (section 3.3). In section 4, we provide a summary and discussion of our results.

\section{Model and Data}

The main part of this paper is based on eight simulations with NIWA-UKCA (denoted as the NIWAUKCA ensemble) a coupled atmosphere-ocean-chemistry-climate model [Morgenstern et al., 2014]. This 


\begin{tabular}{|c|c|c|c|c|c|c|}
\hline $\begin{array}{l}\text { Institute/ } \\
\text { Organization }\end{array}$ & $\begin{array}{l}\text { Model Configuration/ } \\
\text { Simulation }\end{array}$ & $\begin{array}{l}\text { Forcing } \\
\text { Scenario }\end{array}$ & Period & Convective & Figure 6 & Figure $7 / 8$ \\
\hline \multirow[t]{6}{*}{ NIWA } & $\begin{array}{l}\text { NIWA-UKCA, } \\
\text { REF-C2 }(1,2,3)\end{array}$ & $\begin{array}{l}\text { RCP } 6.0 \text { for GHGs, } \\
\quad W M O \text { [2011]for ODSs }\end{array}$ & $1950-2100$ & $X$ & $X$ & $\mathrm{X}$ \\
\hline & $\begin{array}{l}\text { NIWA-UKCA, } \\
\text { REF-C2(4) }\end{array}$ & RCP 6.0, WMO [2011] & $1930-2100$ & $x$ & & \\
\hline & NIWA-UKCA & RCP 6.0, WMO [2011] & $1910-2100$ & $X$ & & \\
\hline & REF-C2(5) & & & & & \\
\hline & $\begin{array}{l}\text { NIWA-UKCA, } \\
\text { SEN-C2-fGHG }\end{array}$ & Fixed GHGs, WMO [2011] & $1960-2100$ & $X$ & & \\
\hline & $\begin{array}{l}\text { NIWA-UKCA, } \\
\text { SEN-C2-fODS }(1,2)\end{array}$ & RCP 6.0, fixed ODSs & $1960-2100$ & $\mathrm{X}$ & & \\
\hline CCMA & CANESM2 & Historical & 1850-2005 & & $\mathrm{X}$ & $\mathrm{X}$ \\
\hline CNRM-CERFACS & CNRM-CM5 & Historical & $1850-2005$ & $x$ & $x$ & $x$ \\
\hline CMCC & CESM & Historical & $1850-2005$ & $x$ & $x$ & \\
\hline CSIRO & ACCESS1.3 & Historical & $1850-2005$ & $x$ & $\mathrm{X}$ & $\mathrm{x}$ \\
\hline CSIRO & MK360 & Historical & $1850-2005$ & $x$ & & $x$ \\
\hline GISS & E2-H-CC & Historical & $1850-2005$ & $x$ & $\mathrm{X}$ & \\
\hline GISS & E2-R-CC & Historical & $1850-2005$ & $x$ & $x$ & \\
\hline IPSL & IPSL-LR-5A & Historical & $1850-2005$ & $x$ & $x$ & $\mathrm{X}$ \\
\hline IPSL & IPSL-MR-5A & Historical & $1850-2005$ & $\mathrm{X}$ & $\mathrm{X}$ & \\
\hline IPSL & IPSL-LR-5B & Historical & $1850-2005$ & $x$ & $x$ & \\
\hline MRI & MRI-ESM & Historical & $1850-2005$ & $\mathrm{x}$ & $\mathrm{x}$ & \\
\hline MPI & MPI-LR & Historical & $1850-2005$ & $x$ & $x$ & $x$ \\
\hline MPI & MPI-MR & Historical & $1850-2005$ & $x$ & $x$ & $x$ \\
\hline NCAR & NCAR-CCSM4 & Historical & $1850-2005$ & & $x$ & $x$ \\
\hline NORESM & NORESM-M & Historical & $1850-2005$ & {$[\mathrm{X}]$} & $x$ & $x$ \\
\hline NORESM & NORESM-ME & Historical & $1850-2005$ & {$[\mathrm{X}]$} & $\mathrm{X}$ & $x$ \\
\hline NOAA-GFDL & GFDL-ESM2-G & Historical & $1861-2005$ & $\mathrm{X}$ & $X$ & $\mathrm{X}$ \\
\hline NOAA-GFDL & GFDL-ESM2-M & Historical & $1861-2005$ & $\mathrm{x}$ & $x$ & $x$ \\
\hline NSF-DOE-NCAR & NCAR-CESM1BGC & Historical & $1850-2005$ & & $x$ & $x$ \\
\hline $\mathrm{MOHC}$ & HADGEM2-CC & Historical & 1859-2005 & $\mathrm{x}$ & $\mathrm{X}$ & \\
\hline $\mathrm{MOHC}$ & HADGEM2-ES & Historical & 1859-2005 & $\mathrm{x}$ & $x$ & \\
\hline
\end{tabular}

model is based on an early version of the HadGEM3 model [Hewitt et al., 2011] and comprises an interactive atmosphere chemistry module, the NEMO ocean model, and the CICE sea ice model [Madec, 2008; Hunke and Lipscomb, 2010; Best et al., 2011; Clark et al., 2011; Hewitt et al., 2011]. Further details of this model setup can be found in Morgenstern et al. [2014]. The simulations used here either follow the Representative Concentration Pathway (RCP) 6.0; [Meinshausen et al., 2011; Eyring et al., 2013] or are sensitivity simulations with either greenhouse gases or ozone-depleting substances held constant. Because we focus on decadal variability and not on long-term forcing trends such differences among ensemble members are considered negligible for our analysis. The simulations cover the period from 1950 to 2100 unless otherwise stated. An eddy parametrization after Gent and McWilliams [1990] is used in the ocean component to compensate for the coarse non-eddy-resolving model grid. In addition to the NIWA-UKCA ensemble, we analyze members of the CMIP5 ensemble for the historical period (1850-2005) and this has been deliberately done to obtain the largest CMIP5 data set. The absence of historical NIWA-UKCA simulations leads to a mismatch between both ensembles with respect to forcing (historical versus RCP 6.0) and simulation period (1850-2005 versus 1950-2100), although both scenarios are identical until 2005. The underlying forcing scenario certainly affects the oceanic background state which leads, under a global warming scenario such as RCP 6.0, to a general weakening of deep convection in the Southern Ocean [de Lavergne et al., 2014]. We use the NIWA-UKCA simulations here to demonstrate the underlying mechanism which can trigger deep convection in this model (i.e., the phase shift between heat and freshwater content south of $67^{\circ} \mathrm{S}$ ). This shift is present over the historical period until 2005 and beyond in all NIWA-UKCA simulations and provides clear evidence that this 


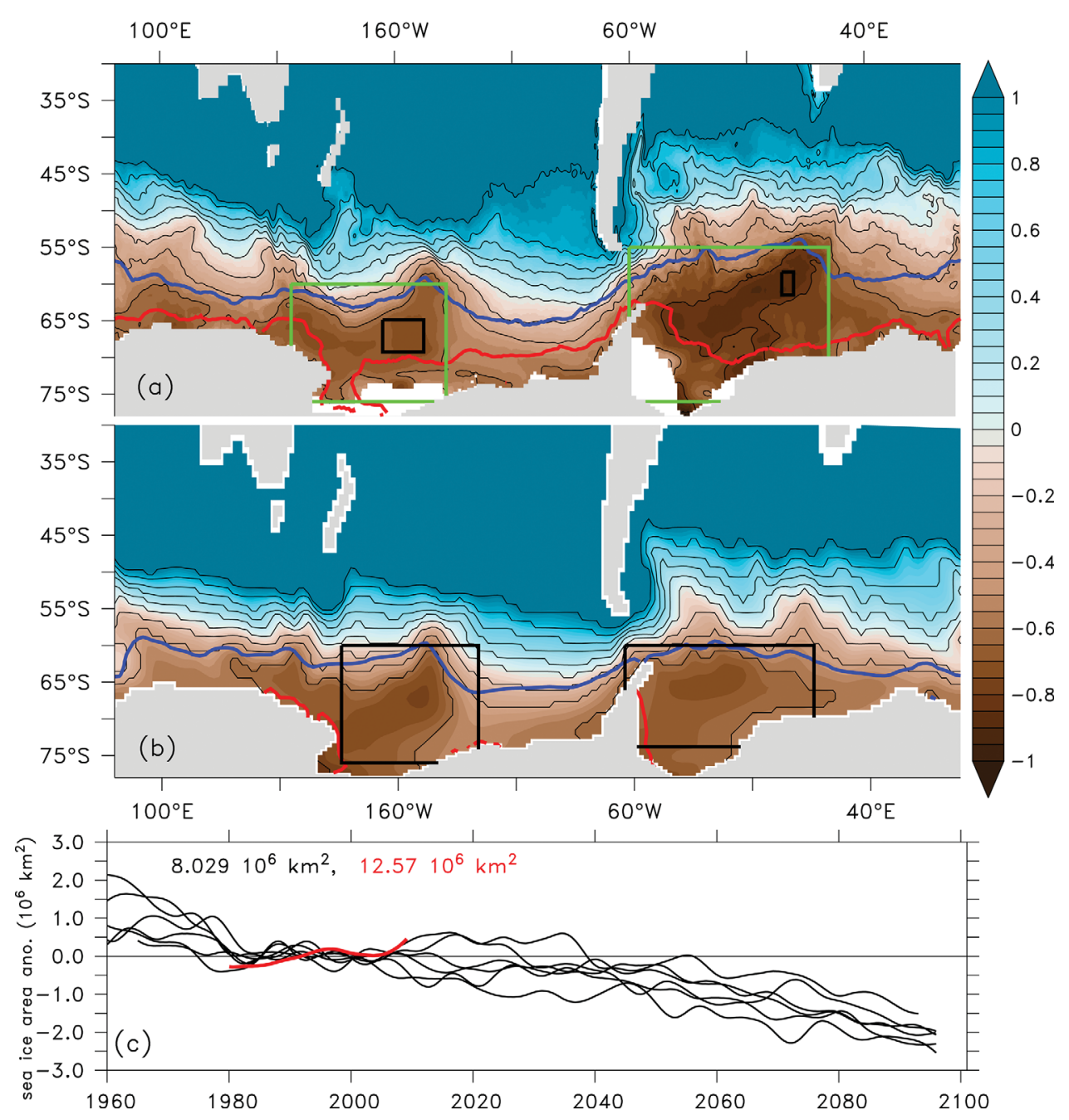

Figure 1. (a) 30 year mean SSH-anomaly (1980-2009) from AVISO in color (in m) and February (red) and August (dark blue) sea ice edges contours from HadISST. (b) Same diagnostic to Figure 1a for NIWA-UKCA-REF-C2(1). Black boxes in Figure 1a indicate regions used to show the connection between changes in SSH and dynamic gyre transports presented in supporting information Figure S1a and S1b. Green boxes indicate regions to evaluate observation used for Figure 9 . Regions indicated by the black boxes in Figure $1 \mathrm{~b}$ are used to compute gyre strength from the coupled models (NIWA-UKCA ensemble and CMIP5). (c) Decadal filtered Southern Ocean sea ice area anomaly (10 6 $\mathrm{km}^{2}$ ) for the NIWA-UKCA ensemble (black) and HADISST (red) for the Southern Ocean, with the time averages for 1980-2008 for NIWAUKCA (black) and HADISST(red) listed at top of this plot.

principal mechanism for triggering convection is not overly impacted by the forcing scenario, although the convection intensity is. By presenting NIWA-UKCA separately to CMIP5 results and by linear detrending relevant time series of both data sources, we try to reduce the mismatch between both ensembles.

A list of all models used in this study is provided in Table 1.

The observational data we use are based on the Hadley Centre Ice and Sea Surface Temperature (HadISST) [Rayner, 2003] and AVISO (http://www.aviso.altimetry.fr/duacs/) climatologies. HadISST provides monthly mean sea surface temperatures (SST) and sea ice concentration (SIC) from 1871 onward at a resolution of $1^{\circ} \times 1^{\circ}$. In sparsely sampled regions, such as the polar seas, assumptions have been made to obtain a global data set and the data prior to the satellite era (1978 -) have to be viewed with great caution. Moreover, some deficiencies have been recognized in HadISST due to a switch of instruments (http://www.metoffice.gov.uk/hadobs/hadisst/). The sea surface height (SSH, AVISO) product used in this study is in the form of monthly means at a resolution of $0.25^{\circ} \times 0.25^{\circ}$, covering the period from 1993 to 2013. 


\subsection{Methods}

In order to investigate decadal to multidecadal variability in the Southern Ocean, we focus on a few key metrics, which appropriately capture the oceanic state in this region. Data availability guides our choice with limitations originating from observations as well as CMIP5 model output. We use monthly means of the following Southern Ocean state variables: subpolar gyre strength, Drake Passage transport, sea ice area, mixed-layer depth, deep convection strength, and the strength of the deep overturning cell associated with the AABW formation. Sea ice area is defined as the area-integral of sea ice concentration above $15 \%$. We define the mixed layers depth (MLD) as the uppermost depth at which the density differs by at least $0.01 \mathrm{~kg} / \mathrm{m}^{3}$ from the surface density, the so-called density criterion. While this definition agrees with Martin et al. [2013] and Heuzé et al. [2015], other studies preferred a density anomaly threshold of $0.03 \mathrm{~kg} / \mathrm{m}^{3}$ [e.g., Heuzé et al., 2013; de Lavergne et al., 2014] often yielding deep winter MLDs. We note this criterion has strong implications, since the Southern Ocean is weakly stratified, and our criterion used here is more sensitive and more restrictive. By integrating $\operatorname{MLDs}\left(>500 \mathrm{~m}\right.$ ) horizontally south of $60^{\circ} \mathrm{S}$, we obtain a ventilated volume or a measure for deep convection strength. Deep convective regions in NIWA-UKCA are typically concentrated near Antarctica and do not reach north of $\sim 65^{\circ} \mathrm{S}$.

We split the CMIP5 models into open ocean convective models and nonopen ocean convective models (in the following referred to as convective and non-convective models, respectively). The aim of this separation is to investigate if models behave differently if they host strong mixing events. This classification is based on results of de Lavergne et al. [2014], and has been further confirmed by an alternative approach presented in this study by mapping MLDs into the temperature-salinity space to analyze the water mass properties formed by convection, although we do note that some studies suggest that there is a smooth transition of models from a convective to a non-convective state [e.g., de Lavergne et al., 2014]. We classify the NIWAUKCA model as convective, since it shows deep convection up to $\sim 2200 \mathrm{~m}$ depth in the Ross and Weddell Seas which spreads out from the coastal polynyas toward the gyre center.

The strengths of the Ross and Weddell Gyres are derived from the barotropic stream function by computing the difference between the coastal values near Antarctica and the maximum values over two different regions in the Ross and Weddell Seas, respectively (regions are shown in Figure 1b, noting that Figure 1 shows SSH and not the barotropic stream function). Positive (negative) gyre strength anomalies reflect anomalously strong (weak) barotropic transport. Similarly, the Drake Passage transport is based on the difference of the barotropic stream function across Drake Passage. The deep overturning associated with the AABW cell is computed using the minimum value of the meridional overturning cell south of $60^{\circ} \mathrm{S}$ and below $500 \mathrm{~m}$ but due to limited model output availability for CMIP5 we only compute this quantity for the NIWA-UKCA ensemble. However, because our simulations suggest a close relationship between convection strength and deep overturning, we use the convection strength as a proxy for deep overturning associated with AABW in CMIP5 simulations. For more details about the overturning in the Southern Ocean, we refer to Downes and Hogg [2013]. All results presented in this paper are based on time series that were linearly detrended and smoothed by a 121 months low-pass Hanning filter, if not stated differently. Our results are not sensitive to our choice of filter and window width.

\section{Results}

\subsection{Decadal Southern Ocean Variability in the NIWA-UKCA-Ensemble}

The dominant circulation feature in the Southern Ocean is the ACC, which is a highly barotropic current, not restricted by any zonal boundary. Its strength is given by the Drake Passage transport at about $136.7 \pm 7.8$ Sv [Cunningham et al., 2003]. The barotropic imprint of this current can be measured by satellite using SSH, which exhibits the current's mostly zonal nature (Figure 1a) as the mean horizontal flow generally follows the SSH contours. Meridional deviations in the current in Figure 1 are likely driven by bottom topography interactions [Sokolov and Rintoul, 2009]. At a smaller-scale, both major subpolar gyres in the Ross and Weddell Seas are characterized by local minima in $\mathrm{SSH}$, in analogy to subpolar gyres in the Northern Hemisphere [Böning et al., 2006]. (Evidence that SSH can be used as a reasonable proxy for the gyre strength is presented in supporting information Figure S1 based on a model hindcast with a horizontal resolution of $0.25^{\circ}$ ) [Behrens, 2013]. Correlations for the Ross and Weddell Gyre are $r=0.5$ and $r=0.84$ between SSH and gyre strength for annual means with no time lag. 


\begin{tabular}{|c|c|c|c|c|c|}
\hline & $\begin{array}{l}\text { Sea Ice Area } \\
\quad\left(10^{9} \mathrm{~m}^{2}\right)\end{array}$ & $\begin{array}{l}\text { Ventilated } \\
\text { Volume }\end{array}$ & Ross Gyre (Sv) & WeddelL Gyre (Sv) & Drake Transport (Sv) \\
\hline OBS & $\begin{array}{c}12.57(1980-2008 \\
\text { HadISST) }\end{array}$ & $\begin{array}{c}(M L D>500 \mathrm{~m} \\
\left.10^{13} \mathrm{~m}^{3}\right)\end{array}$ & $\begin{array}{c}20 \text { Sv (SOSE) } \\
\text { [Mazloff et al., 2010] }\end{array}$ & $\begin{array}{c}40 \text { Sv (SOSE) } \\
\text { [Mazloff et al., 2010] }\end{array}$ & $\begin{array}{c}137 \text { Sv } \\
\text { [Cunningham et al., 2003] }\end{array}$ \\
\hline CANESM2 & 11.68 & 1.52 & 10.84 & 38.06 & 158.14 \\
\hline CNRMCM5 & 7.02 & 16.35 & 30.23 & 50.24 & 91.38 \\
\hline ACCESS13 & 11.65 & 52.24 & 30.43 & 42.72 & 191.12 \\
\hline MK360 & 12.38 & 11.75 & 7.52 & 45.61 & 110.58 \\
\hline IPSL-LR5 & 8.16 & 13.84 & 16.94 & 29.76 & 95.13 \\
\hline MPI-LR & 6.04 & 21.27 & 78.11 & 102.70 & 163.02 \\
\hline MPI-MR & 6.08 & 33.21 & 49.00 & 82.76 & 155.90 \\
\hline CCSM4 & 15.94 & 0.46 & 28.01 & 41.41 & 175.07 \\
\hline NORESM-M & 10.63 & 22.35 & 32.44 & 49.70 & 132.86 \\
\hline NORESM-ME & 14.22 & 9.83 & 31.68 & 69.96 & 132.56 \\
\hline GFDL-G & 6.69 & 331.59 & 12.10 & 37.00 & 119.11 \\
\hline GFDL-M & 4.80 & 206.34 & 10.21 & 22.08 & 132.89 \\
\hline NCAR-CESM1BGC & 15.29 & 1.59 & 28.40 & 44.87 & 169.64 \\
\hline NIWA-UKCA REF-C2(1) & 5.65 & 3.18 & 24.67 & 29.81 & 170.42 \\
\hline NIWA-UKCA REF-C2(2) & 5.49 & 3.43 & 25.41 & 29.58 & 171.21 \\
\hline NIWA-UKCA REF-C2(3) & 5.62 & 2.56 & 23.75 & 29.36 & 170.82 \\
\hline NIWA-UKCA SEN-C2-fGHG & 5.62 & 2.53 & 23.85 & 29.85 & 168.96 \\
\hline NIWA-UKCA SEN-C2-FODS(1) & 6.00 & 3.78 & 21.88 & 27.64 & 176.37 \\
\hline NIWA-UKCA REF-C2(4) & 5.72 & 2.79 & 23.88 & 29.27 & 171.33 \\
\hline NIWA-UKCA REF-C2(5) & 5.83 & 3.27 & 23.57 & 28.98 & 171.37 \\
\hline NIWA-UKCA SEN-C2-FODS(2) & 5.58 & 2.89 & 24.56 & 29.53 & 170.02 \\
\hline
\end{tabular}

${ }^{a}$ Values represent time means for each model simulation and the observational estimates. These values have been also used to scale simulations in Figure 7.

The NIWA-UKCA ensemble (here represented by the REF-C2(1) simulation) captures the large scale circulation quite well, considering the coarse ocean grid of $2^{\circ} \times 1^{\circ}$ of this model version. The strength of both subpolar gyres is well-represented ( $\sim 23 \mathrm{~Sv}$ for Ross and $\sim 30 \mathrm{~Sv}$ for Weddell Gyre in comparison to $\sim 20 \mathrm{~Sv}$ and 40 Sv, respectively based on SOSE [Mazloff et al., 2010], see also Table 2), despite these being quantities which some coupled climate models struggle to represent realistically [Wang, 2013]. Sea ice coverage is underestimated in all simulations of NIWA-UKCA (Figure 1c). This presumably results from a substantial positive SST bias in the Southern Ocean, which many processes likely contribute to [Wang et al., 2014]. While the bias is particularly large ( $95 \%)$ during February when sea ice coverage is at its minimum (red line in Figures $1 \mathrm{a}$ and $1 \mathrm{~b}$ ), the austral winter extent (blue line) is reasonable captured. The NIWA-UKCA ensemble shows an overall decline in sea ice under the RCP 6.0 scenario (black lines), although some individual simulations exhibit periods of increasing sea ice cover, presumably due to decadal variability, similar to some other model simulations [Polvani and Smith, 2013]. Such a declining trend is comparable to the CMIP5 ensemble, but different to the observed sea ice increase of $1 \%$ per decade since about 1980 [Holland and Kwok, 2012] (red line in Figure 1c).

Overall the NIWA-UKCA simulations show distinctly larger variability in the Southern Ocean sea ice cover $\left(\sim \pm 0.510^{6} \mathrm{~km}^{2}\right)$ on decadal timescales than the observations suggest, while the multiannual-mean sea ice cover is $35 \%$ smaller than the observational estimate (which is $12.57 \times 10^{6} \mathrm{~km}^{2}$ ).

Figure 2 shows the decadal variation and relationships of key variables in the Southern Ocean in an arbitrary member of the NIWA-UKCA ensemble (REF-C2(1)). All variables exhibit rich variability on decadal to multidecadal timescales. The most pronounced correlation exists between Southern Ocean sea ice anomalies and Ross Gyre strength (Figure 2a), with a stronger gyre circulation coinciding with positive sea ice anomalies ( $r=0.7$ with a sea ice lag of about 1.25 years). Potential processes that could create this relationship are: wind-driven sea ice divergence, changes in meridional transport of heat and freshwater and open ocean deep convection. We can exclude wind stress as a cause because it is poorly correlated with Ross and Weddell Gyre variability (Figures $2 c$ and $2 d$ ), with a low correlation of $r=-0.18$ and $r=-0.1$, respectively. Both gyres show a similar decadal signal, while the local wind stress curl anomalies differ substantially for both regions. We thus conclude that the effect of local wind stress forcing on the dynamical response of both gyres on decadal timescales is of limited importance, which is in agreement with earlier studies [Wang 

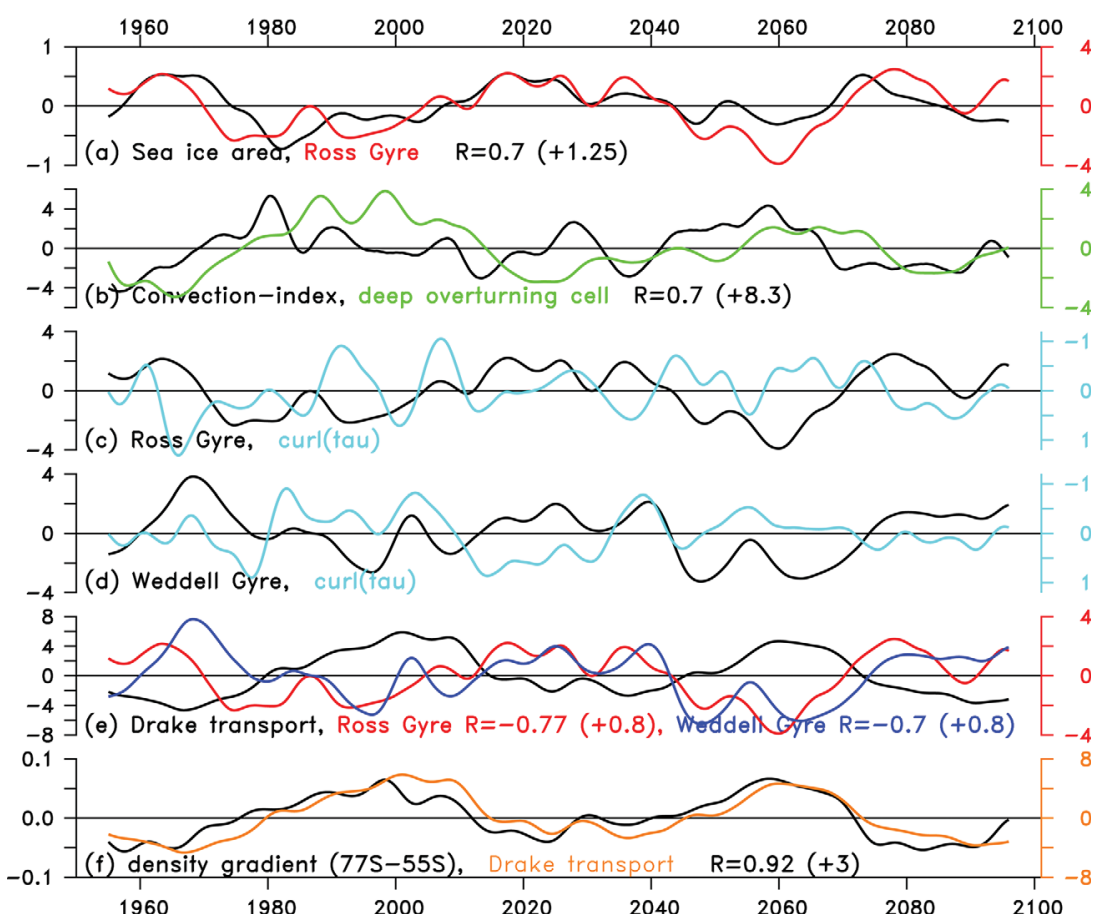

Figure 2. Detrended and decadal filtered Southern Ocean state anomalies for NIWA-UKCA-REF-C2(1): (a) Southern Ocean sea ice anomaly (black, in $10^{6} \mathrm{~km}^{2}$ ) and Ross Gyre anomaly (red, in Sv, positive anomalies indicate a strengthening of the barotropic circulation). (b) Ventilated volume (black, $90^{\circ} \mathrm{S}-60^{\circ} \mathrm{S}$, in $10^{4} \mathrm{~km}^{3}$ ) and deep overturning cell (green, in Sv). (c-d) gyre anomaly (black, in Sv) and wind stress curl anomaly (cyan, in $10^{-8} \mathrm{Nm}^{-2}$ ) for Ross (c) and Weddell (d) Gyre (black boxes in Figure 1b indicate the region for computations of those gyre and wind-stress anomalies). (e) Drake transport (black, in Sv) and Ross (red) and Weddell (blue) Gyres (in Sv, gyre strength scale on the right). (f) Meridional bottom density anomaly between $77^{\circ} \mathrm{S}$ and $55^{\circ} \mathrm{S}$ (black, in $\mathrm{kg} / \mathrm{m}^{3}$ ) and Drake transport (orange, in Sv). Correlation coefficients ( $\mathrm{R}$ ) and lag times (in parentheses) in years also provided.

and Meredith, 2008]. In contrast, decadal variability of sea ice area resembles that of deep convection strength quite well (Figures $2 \mathrm{a}$ and $2 \mathrm{~b}$ ).

Stronger positive (negative) sea ice anomalies coincide with negative (positive) convection anomalies, which are related to the oceanic heat loss during convective periods (Figures $2 \mathrm{a}$ and $2 \mathrm{~b}$ ). Thus, deep convection events are plausible drivers for the variability seen in sea ice area and gyre strength. Convection near the southern rim of the gyre can reduce the meridional density gradient of the gyre, which results in a weakening of the gyre circulation (see supporting information Figure S2 and notes). Mixing of warmer water from mid depth with cold surface water during active convection increases the SST and thus reduces sea ice coverage. Sea ice formation and associated brine rejection at the edges of the convection region, together with large surface heat and freshwater (evaporation) fluxes to the atmosphere, destabilize the water column further. During these convective events dense water is formed, which is reflected in changes of the meridional overturning circulation (deep overturning cell strength, green line in Figure $2 \mathrm{~b}$ ) lagging the convection index (black, line Figure $2 \mathrm{~b}$ ) by 8.3 years $(r=0.7)$. The large-scale density structure and bottom meridional density gradient between $77^{\circ} \mathrm{S}$ and $55^{\circ} \mathrm{S}$ is affected as well (Figure 2f). Ultimately, this change in density gradient directly impacts the Drake Passage transport (black line Figure 2e) which is, to a large part, barotropically driven [Cunningham et al., 2003].

On decadal to multidecadal timescales, the gyre strength varies out of phase to the ACC strength (Drake Passage transport, Figure 2e). We observe a southward migration of the ACC during phases with enhanced ACC and weaker gyre transport. Wang [2013] and Meijers et al. [2012] also noticed a similar behavior for trends in the CMIP5 ensemble, where a stronger ACC occupies a larger area when gyre area and strength decreases.

The analysis of the entire NIWA-UKCA ensemble (Figure 3) confirms the above results. Most importantly, the negative correlation between Drake Passage transport and both the Weddell and Ross Gyre transports is significant (Figures $3 \mathrm{c}$ and $3 \mathrm{e}$ ). As demonstrated above, this link has its origin in the strength and location 

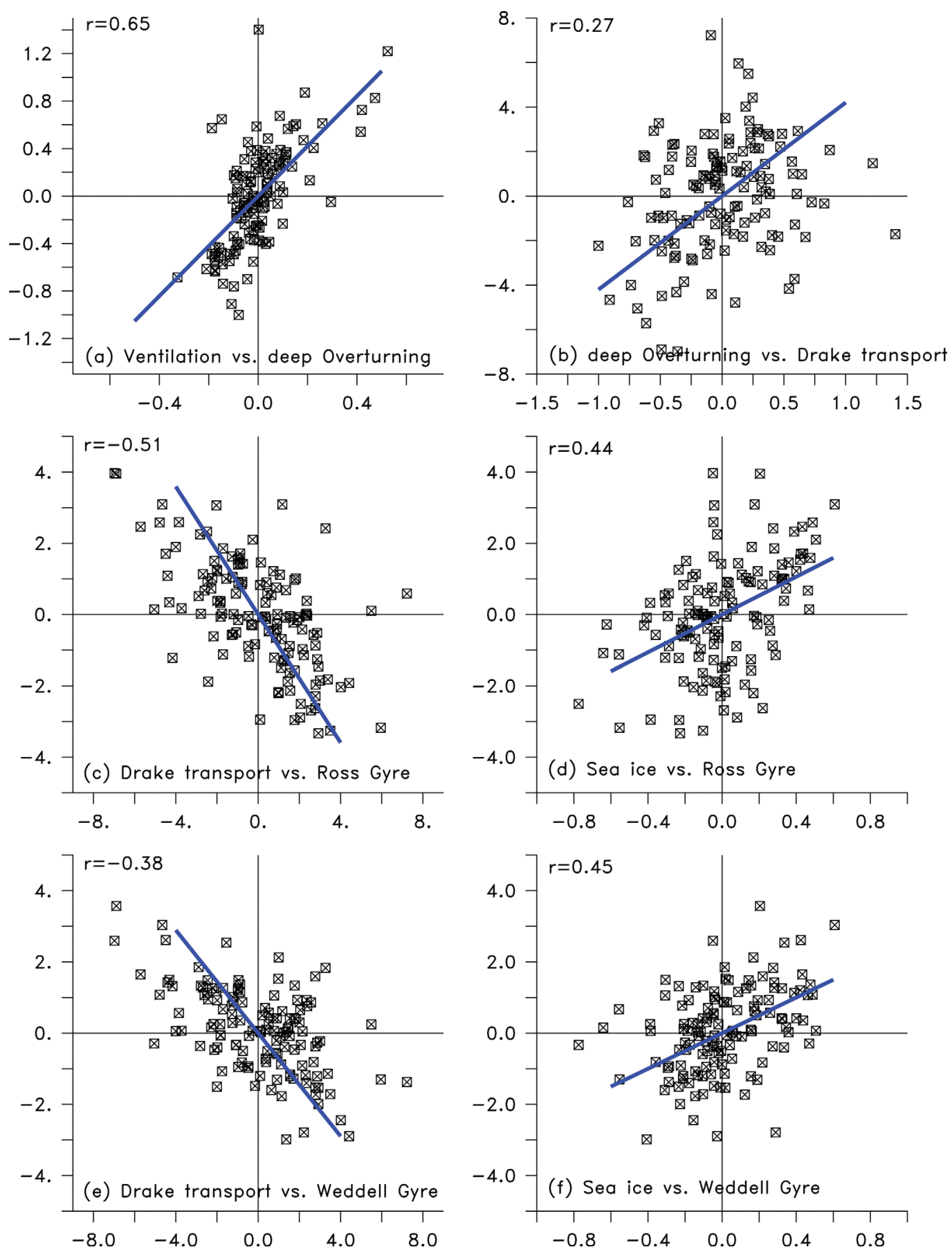

Figure 3. Detrended Southern Ocean state decadal mean anomalies for the NIWA-UKCA ensemble. (a) Ventilated volume (MLD $>500 \mathrm{~m}$, in $10^{5} \mathrm{~km}^{3}$ ) versus deep overturning cell anomaly (Sv), (b) deep overturning cell anomaly (Sv) versus Drake transport anomaly (Sv), (c) Drake transport anomaly versus Ross Gyre anomaly (Sv), (d) Sea ice area anomaly $\left(10^{6} \mathrm{~km}^{2}\right)$ and Ross Gyre anomaly (Sv), (e) Drake transport anomaly versus Weddell Gyre anomaly (Sv), (f) Sea ice area anomaly $\left(10^{6} \mathrm{~km}^{2}\right)$ versus Weddell Gyre anomaly (Sv). Linear fits are drawn in blue, and correlation coefficient $(r)$ shown in upper left corner considering no lag.

of the deep convection, which affects the meridional density gradient (supporting information Figure S2) and highlights the special role of the convection in driving variability in the Southern Ocean on decadal timescales.

The NIWA-UKCA ensemble shows more concentrated convection activity in the Ross than in the Weddell Sea (Figure 4b-4i). Convection reaches down to $\sim 2000 \mathrm{~m}$, covering the southern portion of the Ross Gyre 


\section{QAGU Journal of Geophysical Research: Oceans}

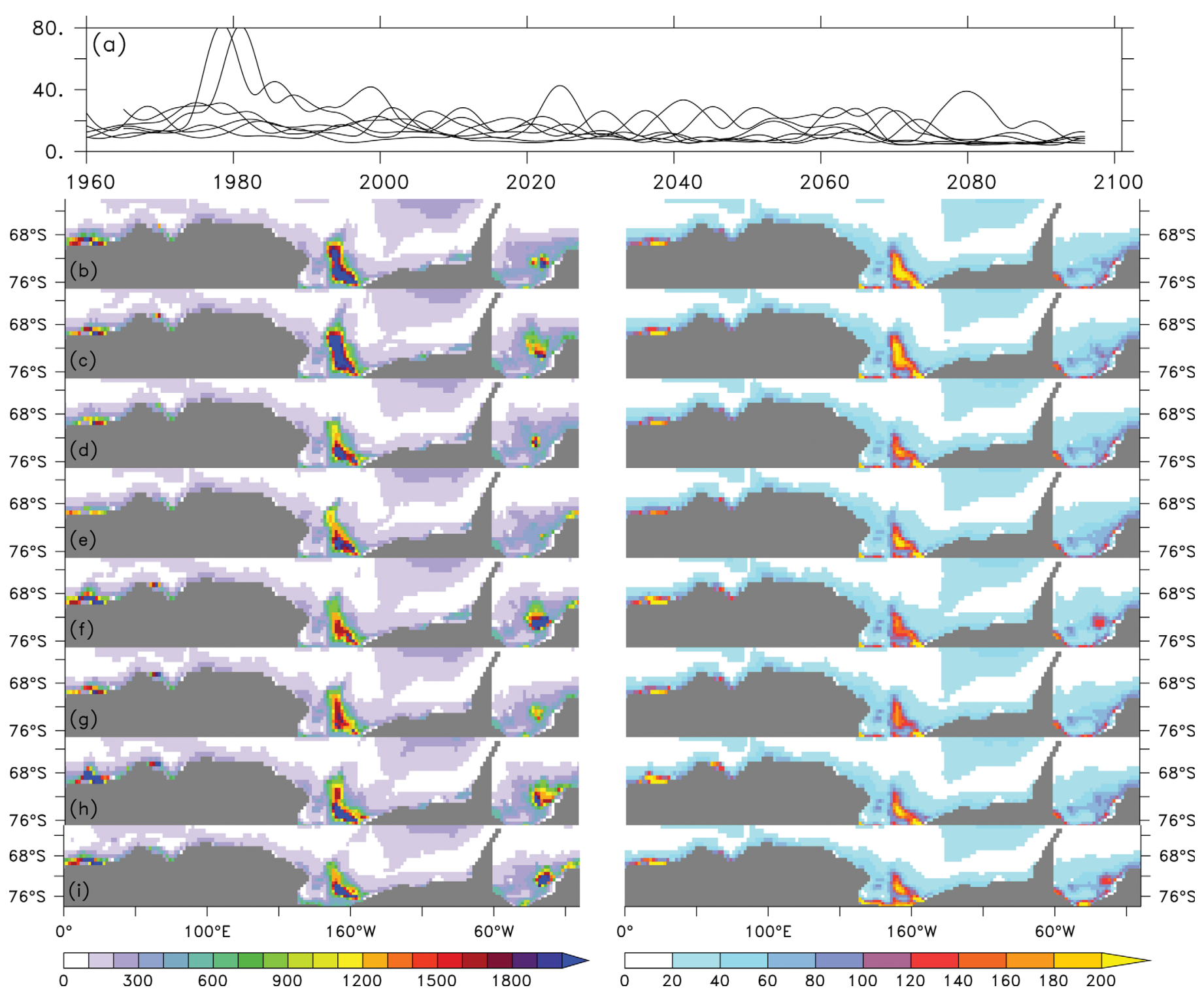

Figure 4. (a) Decadal filtered time series of ventilated volume (MLD's $>500 \mathrm{~m}, 90^{\circ} \mathrm{S}-60^{\circ} \mathrm{S}$, in $10 \mathrm{~km}^{3}$ ) for the NIWA-UKCA ensemble, (b-h) time maximum mixed layer depths (in $\mathrm{m}$, left),

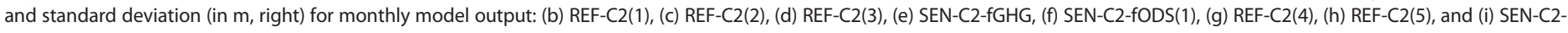
$\operatorname{fODS}(2)$.

in the deeper Ross Sea waters and extending toward the Ross Sea polynya. The area of the Ross Sea polynya during austral winter in the model (defined as the area over which sea ice concentration is less than $70 \%$ ) is at least twice the size of the observational estimate $\left(\sim 30,000 \mathrm{~km}^{2}\right)$ [Martin et al., 2007]. The Ross Sea polynya is essential for the formation of AABW [Jacobs and Comiso, 1989]. In the model, the spurious convective events typically last for up to one decade (Figures $4 a, 5 c-5 e$ ) and are the main trigger for related long-term variability in the other Southern Ocean state quantities. In the NIWA-UKCA ensemble, the overall strength of convection slowly decays over time (Figure 4a), as expected under global warming (RCP 6.0 scenario) as enhanced sea ice melt and increasing SST strengthen the surface stratification. At the same time, reduced sea ice coverage during winter promotes heat losses and thus convection. Nevertheless, the convection intensity exhibits a decadal modulation over the entire simulation period.

We now investigate the open ocean convection events in more detail and explain what triggers their onset in the NIWA-UKCA ensemble. Again, we use model output of an arbitrary NIWA-UKCA ensemble member (REF-C2(1)). We develop the concept described by Martin et al. [2013, 2015] further, where subsurface heat 


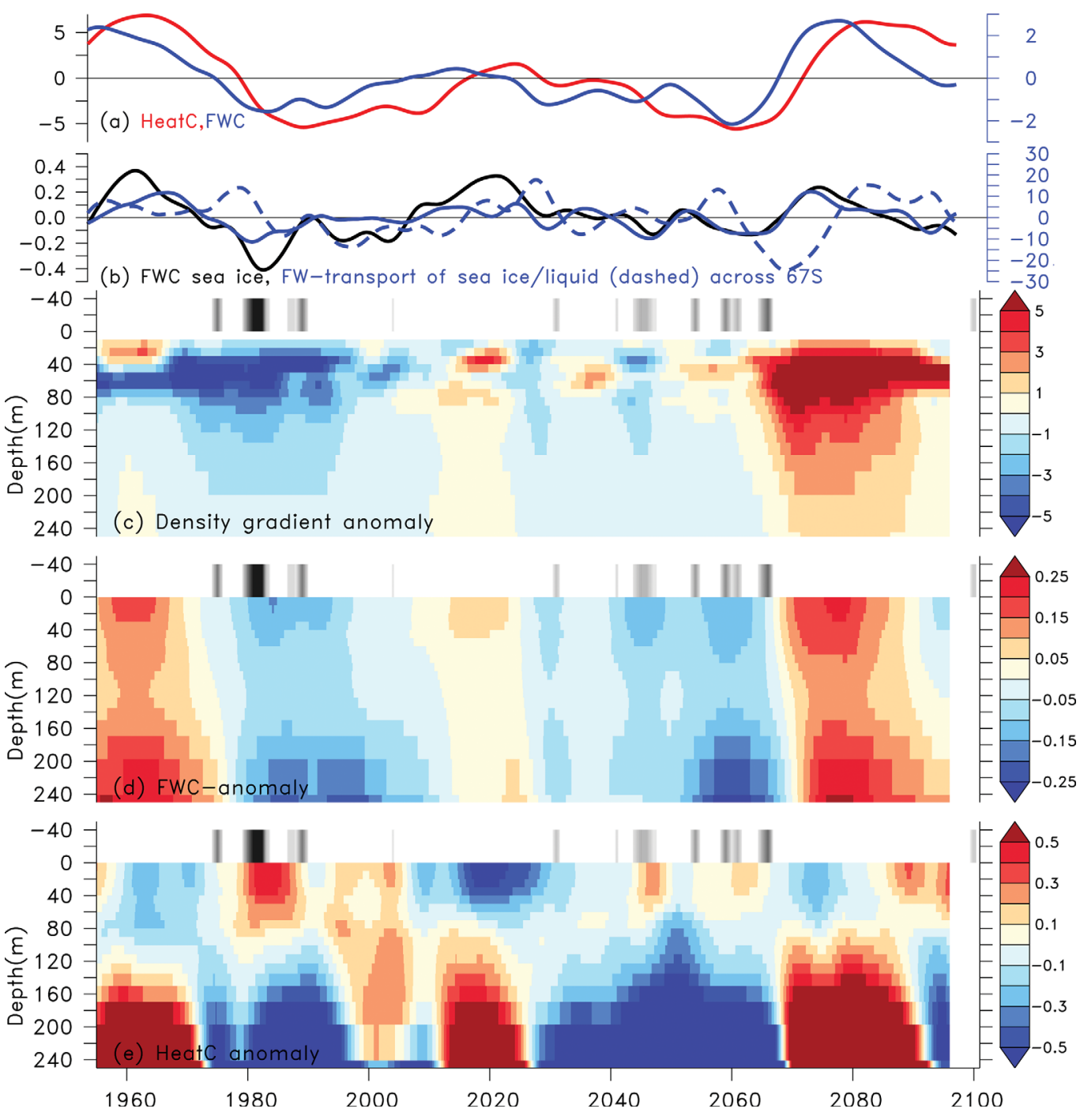

Figure 5. Time mean anomalies between Antarctica and $67^{\circ} \mathrm{S}$ for NIWA-UKCA-REF-C2(1): (a) Integrated oceanic heat (red, in $10^{21} \mathrm{Joule}$ ) and liquid freshwater (blue, in $10^{3} \mathrm{~km}^{3}$ ) content anomaly. See also Figure S3. (b) Freshwater content anomaly associated with sea ice (black, in $10^{3} \mathrm{~km}^{3}$ ) and liquid (blue-dashed) and sea ice (blue solid) freshwater transport across $67^{\circ} \mathrm{S}$ (in $10^{3} \mathrm{~m}^{3} \mathrm{~s}^{-1}$ ). (c) Vertical density gradient anomaly $\left(10^{-4} \mathrm{~kg} / \mathrm{m}^{4}\right.$, positive anomalies represent a strengthening of the stratification); (d) Vertical freshwater content anomalies (in $\left.10^{3} \mathrm{~km}^{3}\right)$; (e) Vertical heat content anomalies (in $10^{20}$ Joule); The grey to black color gradient at the top of Figures $5 \mathrm{c}-5 \mathrm{e}$ indicates the strength of deep convection (darker is stronger, calculated from the ventilated volume where MLD exceeds $500 \mathrm{~m}$ ); All diagnostics have been decadally filtered and detrended. For freshwater calculations, $\mathrm{S}_{\text {ref }}=35.0$ is used.

content is the main driver for convection. We show that sea ice-related freshwater export can contribute to an additional weakening of the stratification and thus promoting convection. In addition, we demonstrate that variability on shorter than centennial time scales can be stimulated by these convective events. In the example in Figure 5a, we see large decadal to multidecadal variability in the heat and liquid freshwater content south of $67^{\circ} \mathrm{S}$.

This latitude threshold allows us to obtain a clear signal associated with open ocean deep convection, which is mainly located south of this latitude band. Note, a few regions known for near-coastal deep water formation (e.g., Cape Darnley), where NIWA-UKCA also suggests convection activity (Figure 4), are not included. Moreover, the Ross Gyre centre is also located at about $67^{\circ} \mathrm{S}$, most of the Weddell Gyre is included, and the influence of the ACC is largely avoided.

In Figure 5a, a distinct phase shift of 5-10 years can be seen between the heat and freshwater content signatures with the freshwater content always leading. This is a consistent feature across all members of the NIWA-UKCA ensemble (supporting information Figure S3). The variation in the length of the time shift are 
likely related to a complex interaction between subpolar gyre strength and the deep overturning cell, and the associated meridional heat and freshwater transport. The phase shift itself is introduced by the combination of liquid and solid freshwater transports across $67^{\circ} \mathrm{S}$ (Figure $5 \mathrm{~b}$ ). Both have the same magnitude but sea ice transport is more effective as it unavoidably affects the oceanic stratification, whereas this is conditional for the liquid transport. The sea ice related freshwater transport across $67^{\circ} \mathrm{S}$ appears to be affected by both the gyre circulation and the direct surface wind forcing. We also note that the liquid transport sometimes counteracts the solid (sea ice) contribution, but the close match between sea ice-related freshwater transport and the liquid freshwater content anomaly (Figure 5a) implies that the residual flux (evaporation minus precipitation plus river runoff) must have the same sign as sea ice freshwater transport in order to close the freshwater content budget. The associated sea ice heat transport is small however, so sea ice export anomalies mainly affect the freshwater content but not the heat content.

During periods with positive sea ice anomalies (black curve in Figure 5b, e.g., 1955-1975) and stronger gyre circulation (Figures $2 \mathrm{c}$ and $2 \mathrm{~d}$ ), the sea ice and associated freshwater export to the north is enhanced (blue solid), reducing the local freshwater content while the heat content is still growing at depth (Figures $5 \mathrm{~d}$ and $5 \mathrm{e}$, see also the phase lag between freshwater and heat content in the ensemble members in supporting information Figure S3). The combination of both leads to a weakening of the stratification and promotes deep convective events as described in the example provided below.

We note distinct positive stratification anomalies around 1960, 2000, 2020, 2035, 2055, and from 2060 onward in the upper $100 \mathrm{~m}$ of the water column (Figure $5 \mathrm{c}$ ). The negative anomalies in between coincide with deep convection events and are indicated by grey-shaded stripes at the top of each plot; the darker the shading, the more intense the convection. All positive stratification anomalies go along with an increase of the freshwater content (which does not mean that freshwater anomalies are positive (e.g., 2035), Figure $5 \mathrm{~d}$ ). Positive heat content anomalies of the upper $100 \mathrm{~m}$ can be related to active deep convection in most instances and coincide with cold anomalies below (Figure 5e). The heat anomalies are thus interpreted as a result of deep mixing. The phase shift and the earlier occurrence of the freshwater anomalies highlight the role of freshwater as a driver of positive upper ocean stratification anomalies, which precede strong convective events. Potential sources of these freshwater anomalies are meridional transports and/or local surface fluxes.

Focusing on the 1960s stratification anomaly, a positive freshwater content anomaly is present at all depths. The heat content, however, shows a distinct reduction in the upper $100 \mathrm{~m}$ and a significant increase below $140 \mathrm{~m}$ (Figures $5 \mathrm{c}-5 \mathrm{e}$ ). The surface freshening prevents deep convection and enables heat accumulation at middepth similar to the processes described by Martin et al. [2015]. Around 1960, the freshwater stored in sea ice reaches its maximum (black line in Figure $5 b$ ) and an increasing export of sea ice/freshwater occurs thereafter (blue solid line). Enhanced sea ice-related freshwater transport and a growing subsurface heat content weaken the stratification further. In the mid-1970s, integrated heat content peaks (red line in Figure 5a) and the upper ocean heat content anomalies begin to turn positive, suggesting that the heat stored at middepth has overcome the pycnocline and deep mixing occurs (Figure 5e). This heat reduces the sea ice coverage and triggers deep convection (grey bars, $\sim 1975, \sim 1980, \sim 1995)$. Consequently, subsurface heat is released to the atmosphere and the integrated heat content reaches a minimum in 1990 (Figure 5a). Deep convection stops when the heat content is exhausted and surface freshwater content increases again (Figures 5d and 5e), in line with findings by Martin et al. [2013] on centennial timescales. The same mechanism can be seen for positive stratification anomalies in 2020 and from 2070 onward. During the convective period of 2040 and 2060, no positive temperature content anomalies at depth are observed, which would explain the weak deep convection intensity in these years (grey bars).

We conclude that (surface) freshwater anomalies (which are partly associated with storage in sea ice and its transport) and related positive surface to subsurface stratification anomalies are critical for triggering the heat accumulation that drives intense deep convection. The heat accumulation at middepth, which is fueled by meridional heat transport, sets the duration and intensity of the convective period.

\subsection{Decadal Southern Ocean Variability in CMIP5 Simulations}

The lack of a full model output set from the selected CMIP5 simulations prevents us from repeating the above detailed analysis to test if the mechanisms will be similar in the majority of cases where freshwater fluxes from sea ice dominate the convection process. Results from Martin et al. [2013] and Stössel et al. [2014], 
however, suggest the mechanisms are similar. In this section, we restrict ourselves to investigate decadal variability in processes such as the strength of subpolar gyres, sea ice area, and Drake Passage transport. We investigate if convective models will behave differently to nonconvective models and, in addition, if convective models show larger variability. In this section, we compare CMIP5 results with those of the NIWA-UKCA ensemble to gain information about uncertainties, and to place the results presented above in the broader multimodel context.

We quantify and illustrate open ocean convection in the CMIP5 models, and in the NIWA-UKCA ensemble, in a different way to previous studies [Heuzé et al., 2013; de Lavergne et al., 2014], by using sea surface salinity and temperature to map MLD (>500 m) in TS space (Figure 6). We can thus quantify ventilated volume in relation to temperature, salinity, and density properties for each model. This approach also allows us to assess both the spread of the simulated deep convection and potentially AABW formation rates. Convective models usually show local maxima of high-ventilated volume, or multiple maxima, mainly associated with higher temperature and salinity and lower density characteristics compared to observed AABW properties (observed AABW temperature and salinity properties are marked by the red circle $\left(\mathrm{T}=1.7^{\circ} \mathrm{C}, \mathrm{S}=34.61 \mathrm{psu}\right.$ [Fahrbach et al., 1995]) in Figure 6). Interestingly, the categorization into convective and nonconvective models from this diagnostic is very similar to the one suggested by de Lavergne et al. [2014] (Table 1). Our diagnostic only adds the NORESM models to the group of convective models. We identify the following convective models with either an overly excessive convective volume or an additional local maxima not matching observed AABW properties or both: ACCESS13, CMCC-CESM, CNRM-CM5, GFDL-ESM2G, GFDLESM2M, GISS-E2-H-CC, GISS-E2-R-CC, HADGEM2-CC, HADGEM2-ES, IPSL-CM5A-MR, IPSL-CM5A-LR, IPSLCM5B-LR, MPI-ESM-LR, MPI-ESM-MR, MRI-ESM, NORESM-M, NORESM-ME, and NIWA-UKCA REF-C2(1). Models which show a similar convection pattern to the reference observational data (WOA13, bottom left) in terms of convective intensity, temperature, and salinity properties are CCSM4, CESM1BGC, and partly CCCMACANESM. In all convective models, the convective volume exceeds $10^{12} \mathrm{~m}^{3}$ and the strongest convection occurs when temperature and salinity properties are in the Circumpolar Deep Water range. The results also show that the NIWA-UKCA simulation is among the models with relatively moderate levels of convection activity in contrast to clear strong convective models such as the Goddard Institute of Space Studies (GISS) model (see also Table 2 where volumes with ventilated water exceeding $>500 \mathrm{~m}$ are included). Based on this diagnostic, CESM1BGC and CCSM4 show the best quantitative match with World Ocean Atlas (2013) data with respect to the location, intensity of convection and time-mean temperature, and salinity properties (represented by the grey dots). We thus conclude that models which do simulate surface temperature and salinity properties well, generally do not show overly strong deep convection. On the other hand, wellrepresented surface properties do not necessarily imply good representation of deep properties [Heuzé et al., 2013]. (We note that the subsampling of temperature and salinity data for plotting the surface means that, for some models, the time-mean properties of temperature and salinity do not overlap with the convection activity.)

In the following sections, we present evidence for deep convection events stimulating decadal to multidecadal variability in the CMIP5 models. Due to restrictions of the available CMIP5 output, we focus in the following only on a subset of state variables. We detrend and filter the diagnostic time series using a 121 months Hanning filter. We then compute standard deviations from those time series and scale them with the individual model mean value (Figure 7, see Table 2 for model mean values). Additionally we group them into either convective or nonconvective CMIP5 models, or NIWA-UKCA ensemble.

Figure 7 shows that nonconvective models (denoted by black dots following the classification of de Lavergne et al. [2014] for improved comparability) have a relatively small "convection variability" index (abscissa) and in most cases also small variability associated with convection in other Southern Ocean state variability indices, like sea ice (Figure 7a), Drake Passage transport (Figure 7b), Ross Gyre (Figure 7c), and Weddell Gyre (Figure 7d) transports. In contrast, convective models (red dots) tend toward larger variability than nonconvective models in sea ice area, gyre, and Drake Passage transport variability. Their variability exceeds the upper limit of nonconvective models, with the NORESM models (\#9, \#10) marking the transition. NORESM are nonconvective models after de Lavergne et al. [2014] but could, after results presented in Figure 6, be classified as convective. The NIWA-UKCA ensemble (blue dots) sits on the fence between convective and nonconvective models and provides a measure of the ensemble spread. This spread is substantial, though the ensemble members do have different and continuously varying forcing conditions imposed 


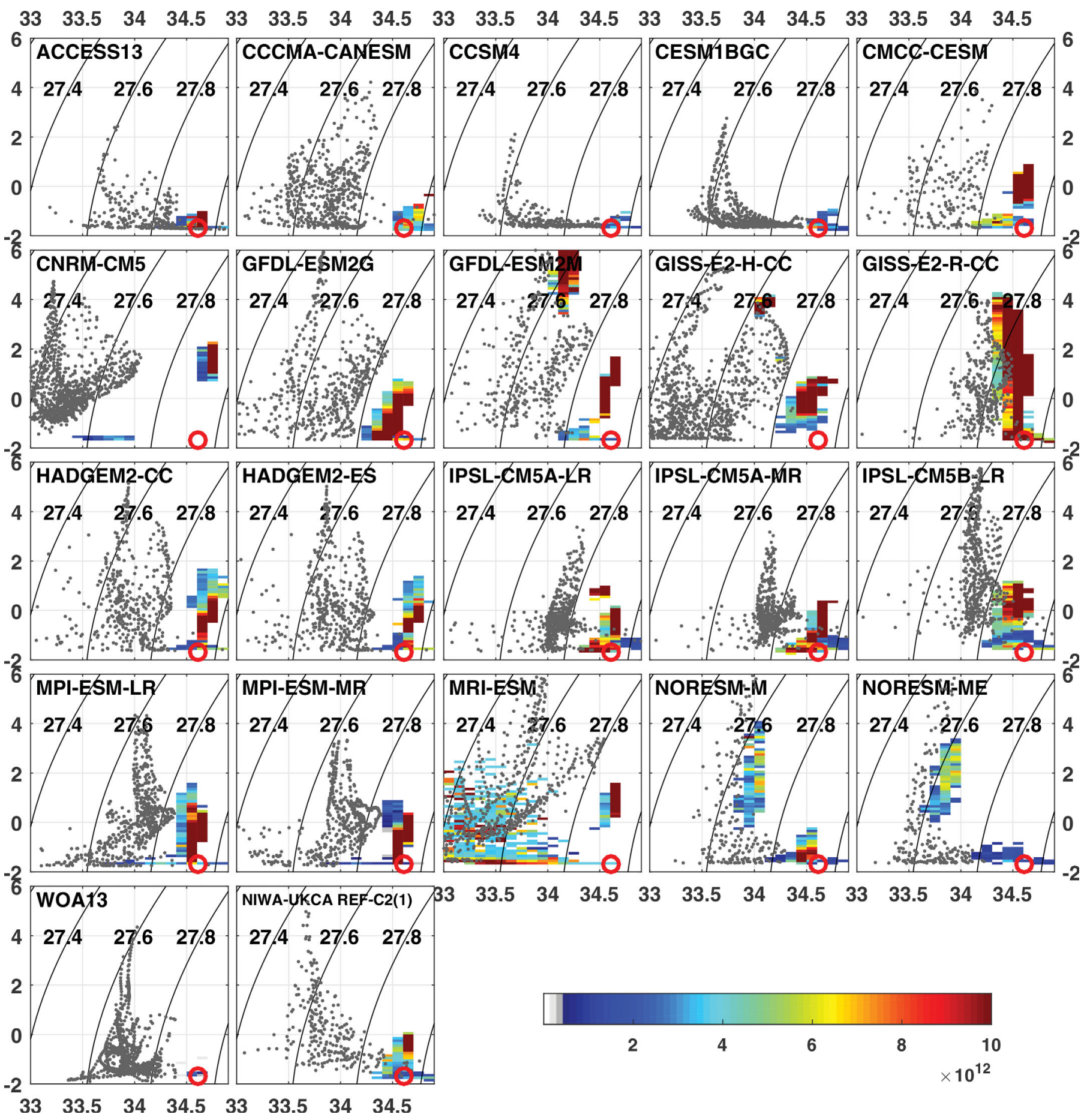

Figure 6. Time mean ventilated volume (in $\mathrm{m}^{3}$ ) in TS space for selected CMIP5 models, World Ocean Atlas 2013, and NIWA-UKCA-REF-C2(1) south of $\sim 60^{\circ} \mathrm{S}$. Grey dots show time mean surface temperature and salinity properties for each model, illustrating water mass properties. Surface salinity and temperature have been used for remapping MLD ( $>500 \mathrm{~m}$ ) into the TS-space. Red circles indicate AABW properties $\left(\mathrm{T}=-1.7^{\circ} \mathrm{C}, \mathrm{S}=34.61 \mathrm{psu}\right.$ ) in its formation region (Weddell Sea) [Fahrbach et al., 1995]. Black contour lines indicate isopycnal surfaces $\left(\sigma_{0}\right.$, in $\left.\mathrm{kg} / \mathrm{m}^{3}\right)$.

through RCP 6.0 and through ozone changes. Convective models show-with exception of ACCESS13 (\#3)-larger sea ice variability than nonconvective models (Figure 7a). The same applies to Drake Passage transport variability, with the exception of MPI-LR (\#6) (Figure 7b). The Ross Gyre in CANESM2 (\#1) and MK360 (\#4) (both are nonconvective models) shows similar variability to convective models (Figure 7c). MK360 hosts deep mixed layers in this region, in contrast to CANESM [Sallée et al., 2013] and thus the 

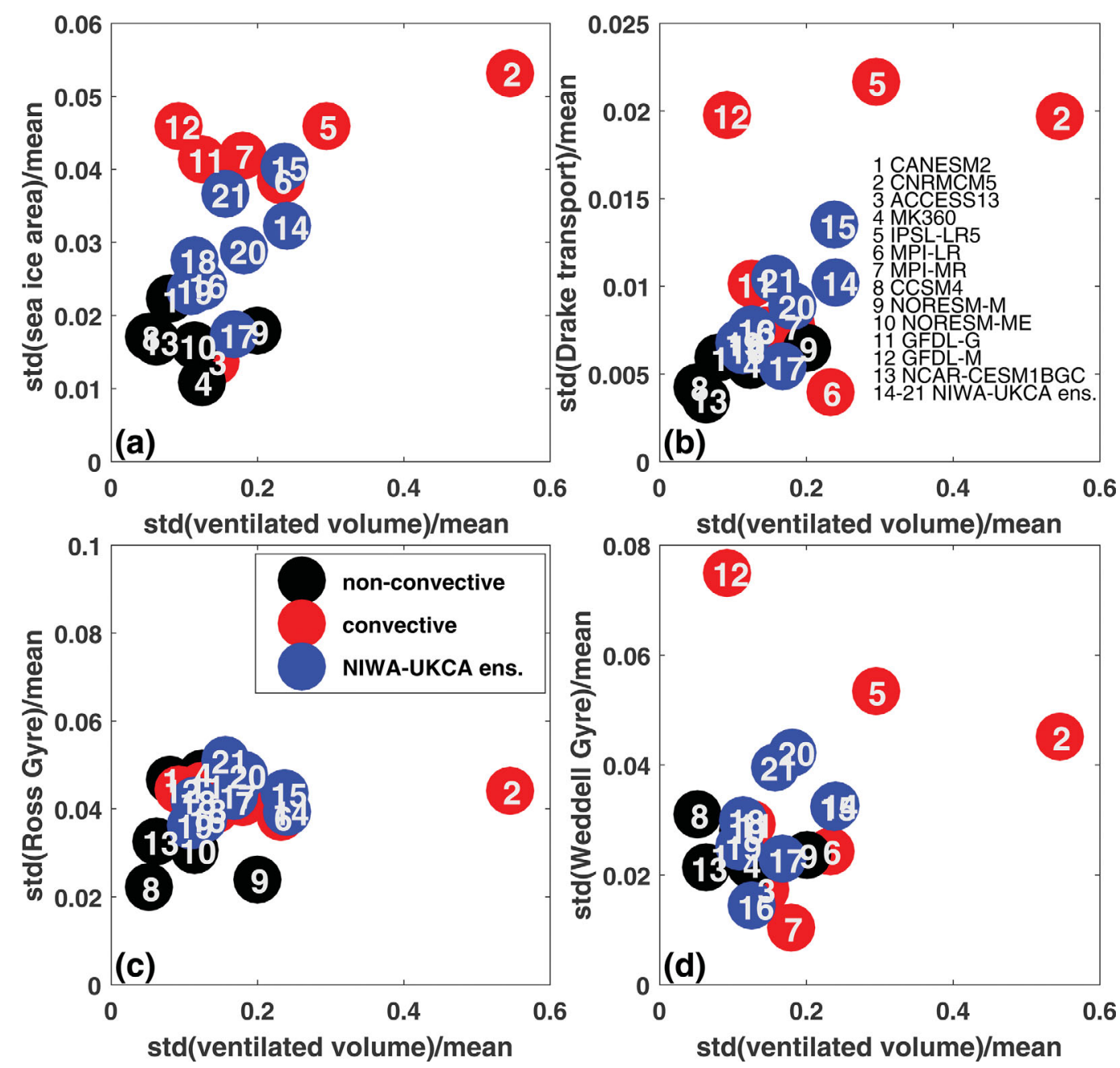

Figure 7. Standard deviations of Southern Ocean state quantities of CMIP5 models and NIWA-UKCA ensemble (blue dots) divided by the individual mean value (see Table 2). Convective models are represented by red dots and nonconvective models by black dots following the classification by Lavergne et al. [2014]. Time series have been detrended and decadal filtered before computing standard deviations. (a) Ventilated volume (MLD $>500 \mathrm{~m}$ ) versus sea ice area, (b) Ventilated volume (MLD >500 m) versus Drake transport, (c) Ventilated volume (MLD > $500 \mathrm{~m}$ ) versus Ross Gyre, (d) Ventilated volume (MLD >500 m) versus Weddell Gyre. For the ventilated volume, MLD's south of $60^{\circ} \mathrm{S}$ are considered.

reason for the enhanced variability remains unclear. For the Weddell Gyre, results show an even larger spread. The only convective models which exhibit larger Weddell Gyre variability than nonconvective models are GFDL-M (\#12), IPSL-LR5 (\#5), and CNRMCM5 (\#2) (Figure 7d). Only GFDL-M hosts deep mixed layers in this region which could explain the larger gyre variability, but not the behavior of the other two models. MPI-MR(\#7) on the other hand shows intense deep convection in this region but small Weddell Gyre variability which can only be explained by persistent convection activity in this model. Deep convection certainly has an impact on the gyre circulation by changing the density structure, but cannot explain the gyre variability seen in models entirely. Overall the results suggest that (open ocean) convection is a potential driver for variability in Southern Ocean state variables on decadal to multidecadal timescales in CMIP5 simulations.

We now consider whether relationships found in the NIWA-UKCA ensemble between Southern Ocean state variables also exist in the selected CMIP5 simulations. We use cross correlations of detrended and decadally filtered time series. The linear fit of these cross correlations between the minimum and maximum range of each model (Figure 8) can indicate if both state variables/quantities covary. We further separate models into nonconvective and convective models (accordingly labeled, based on the classification by de Lavergne et al. [2014]) to investigate if relations depend on the convective state of a model and if strong convective 

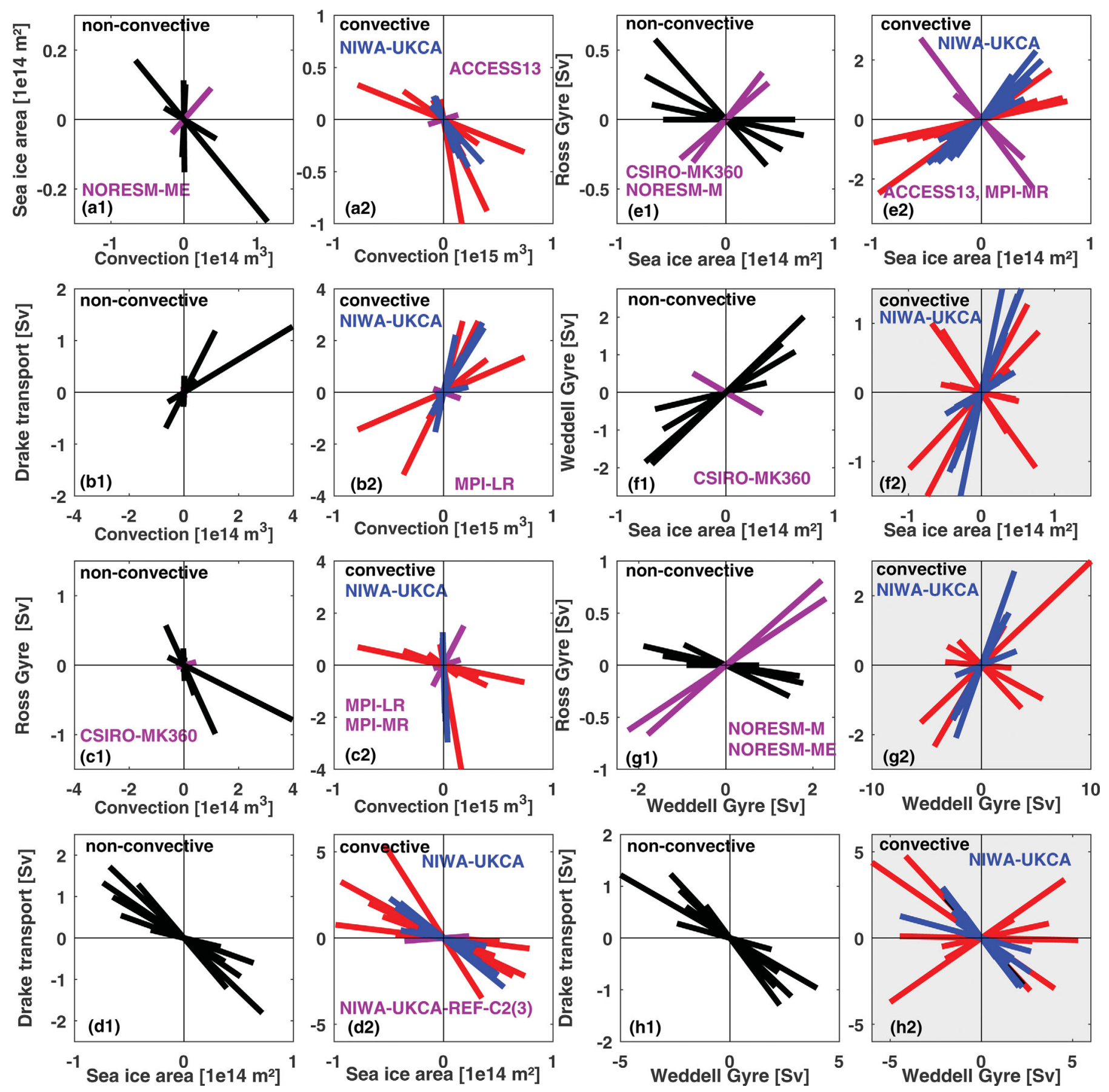

Figure 8. Linear regressions of covariability of Southern Ocean state quantities. Regressions have been computed from linear detrended and decadal filtered time series. Individual model minimum and maximum values have been used for plotting the linear fit. NIWA-UKCA ensemble (blue lines), nonconvective models (black lines), convective models (red lines). The classification follows de Lavergne et al. [2014]. Relations for nonconvective and convective models have been separately displayed. Exceptions from multimodel behavior are

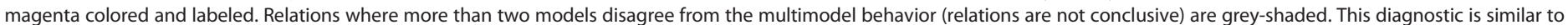
Figure 3 , but only the linear fit for each model is shown.

events force certain dependencies. The separation into different groups also allows for a larger range as convective models normally show a higher degree of variability and thus larger extreme (minima and maxima) values. Outliers from the general ensemble behavior are colored magenta, labeled by model and included. If more than two models disagree with the CMIP5 group behavior, we conclude that the dependency between the two variables is not robust and use a grey background in the Figure 8 subplot. This diagnostic study does not take phase shifts (delayed responses) into account, which could have an impact on 
the results. There is little consistency among the selected CMIP5 models and the codependencies between variables in general; however, this agrees with findings of earlier studies that also noticed a large spread in model behaviors [Meijers et al., 2012; Wang, 2013] for the Southern Ocean.

In the following section, we only focus on relations between Southern Ocean quantities where at least one ensemble of either convective or nonconvective model shows a consistent link. Most models exhibit a negative relationship between convection strength and sea ice cover (Figures 8a1and 8a2). Convection activity causes vertical mixing which results in warmer SST and thus reduced sea ice cover. As outlined above in section 3.1 (Figure 5), increasing stratification due to freshwater fluxes and partly melting sea ice can lead to the onset of deep convection by causing an imbalance between surface and meridional heat and freshwater fluxes. The clearest signal is expected and seen in the convective models. Clear deviation from this multimodel behavior is only demonstrated in the NORESM-ME and ACCESS13 simulations. The reasons for this remain unclear and cannot be related to obvious differences (e.g., overall sea ice area and strength of convection) when compared to other models in their respective subgroups. Convection activity, and thus the formation of dense water, affects the meridional density gradient across the ACC with implications for the Drake Passage transport. Convective and nonconvective models show, therefore, a positive relationship (Figures $8 \mathrm{~b} 1$ and $8 \mathrm{~b} 2$ ) between both. Such a connection is also found in high-resolution models [Howard et al., 2015]. An opposing behavior occurs in the MPI-LR simulation, where positive convection anomalies lead to negative Drake Passage transport anomalies. The strong deep convection in this model is located in the Weddell Gyre and the Drake Passage transport (in the order of $163 \mathrm{~Sv}$ ) is at the upper end of model solutions. However, this also applies to other models which show a positive relationship (e.g., MPI-MR). A negative relationship between convection and Ross Gyre strength is present in most of the convective and nonconvective models (Figure $8 \mathrm{c} 1$ and $8 \mathrm{c} 2$ ), possibly due to the mechanism found in the NIWA-UKCA ensemble (supporting information Figure S2). Exceptions are CSIRO-MK360 and both MPI models. The latter are known to host strong convection in the Weddell Gyre but not in the Ross Sea region. The same diagnostic for the Weddell Gyre is not conclusive for either model ensembles, convective, or nonconvective (not shown in Figure 8). The negative relationship between sea ice and Drake Passage transport (Figures 8d1 and $8 \mathrm{~d} 2$ ) is explained by the relationship between the convection and sea ice, and convection and Drake Passage transport, presented above. A further explanation is based on results by Meijers et al. [2012], who find that a stronger ACC expands meridionally and thus pushes sea ice southward, causing a negative sea ice anomaly. Only the NIWA-UKCA-REF-C2(3) simulation deviates from this multimodel behavior, showing slightly increased Drake Passage transports during positive sea ice anomalies in contrast to the ensemble members with identical model set up NIWA-UKCA-REF-C2(1-5). A clear reason for this divergence was not identified but this behavior perhaps shows the weakness of this diagnostic in combination with short-time series.

Motivated by the NIWA-UKCA results presented in Figure 3, we relate the Ross Gyre strength to the overall sea ice cover. Results show that the tendency between convective and nonconvective models does not agree (Figures $8 \mathrm{e} 1$ and $8 \mathrm{e} 2$ ), although the behavior is consistent within the individual ensembles (based on our selected criterion). Nonconvective (convective) models show a negative (positive) relationship between sea ice and Ross Gyre strength. By contrast, the nonconvective models suggest a positive relation between Weddell Gyre strength and sea ice; this relationship is not conclusive (grey-shaded) for convective models (Figures $8 \mathrm{f} 1$ and $8 \mathrm{f2}$ ). The positive link between Ross and Weddell Gyre anomalies found in the NIWA-UKCA ensemble is not supported by the convective ensemble (Figure $8 \mathrm{~g} 2$ ), and the nonconvective models even suggest an anticorrelation between the two (Figure $8 \mathrm{~g} 1$ ). It also remains unclear as to why only nonconvective models and the NIWA-UKCA ensemble show a negative relationship between Weddell Gyre and Drake Passage transport (Figure 8h1) and why this link is not supported by the convective models (Figure 8h2). A possible explanation could be the location where convective models perturb the gyre-either in the gyre centre or the gyre rim-leading to a different gyre circulation response (see supporting information Figure S2). We conclude that many of the relationships presented in Figures $8 \mathrm{e}-8 \mathrm{~h}$ are highly affected by modelspecific factors (e.g., region and intensity of convection occurrence and sea ice distribution), which are hard to disentangle for each model and is beyond the scope of this study. However, we have been able to confirm some relationships between Southern Ocean state variables in other CMIP5 simulations (as was suggested by NIWA-UKCA ensemble (Figure 3) which are predominantly in line with earlier findings by Meijers et al. [2012]). 

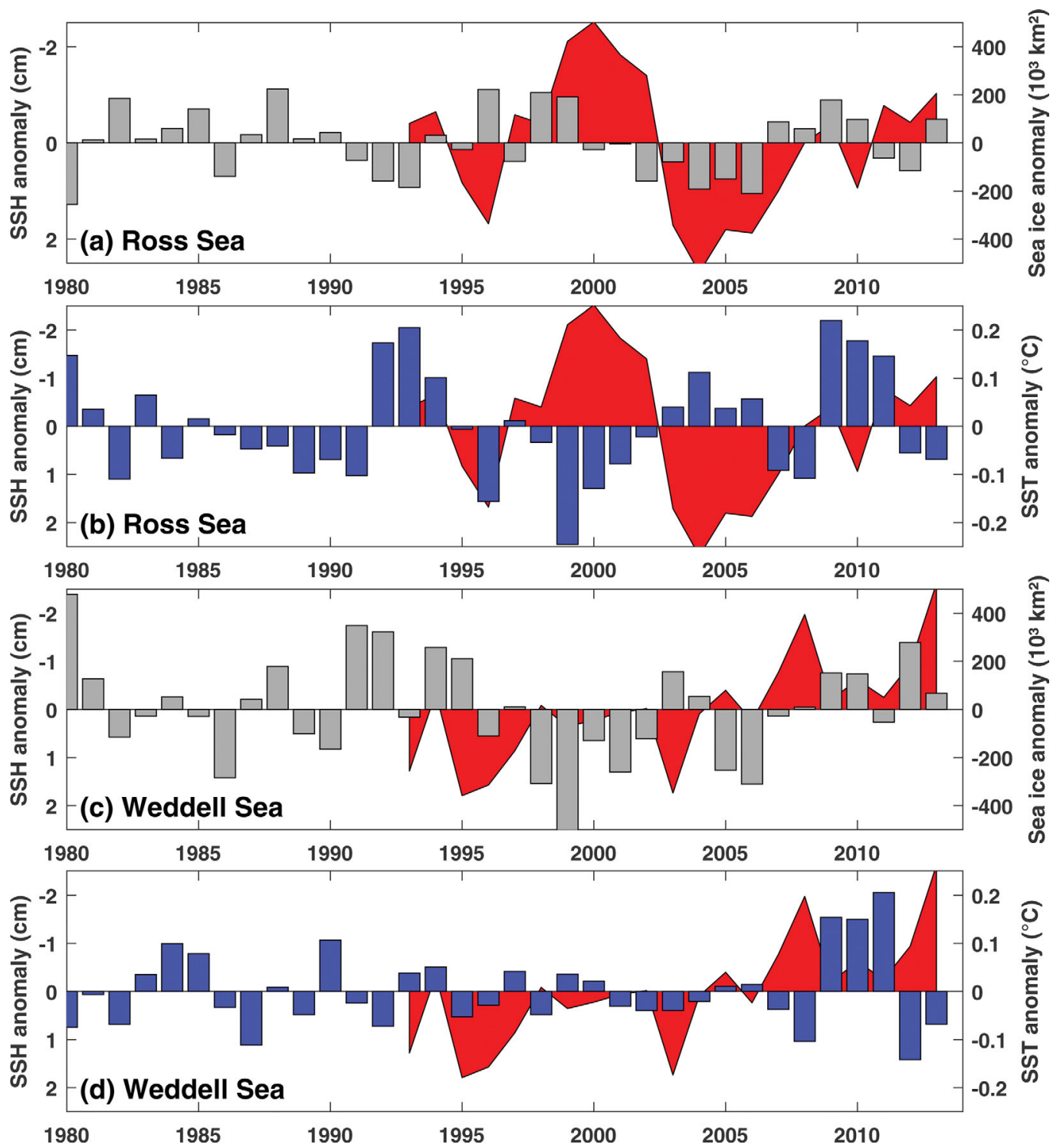

Figure 9. Detrended annual mean sea ice anomaly (grey bars, in $10^{3} \mathrm{~km}^{2}$, right scale), annual SST anomaly (blue bars, in ${ }^{\circ} \mathrm{C}$, right scale) both from HadISST and February SSH anomaly (red shading, in cm, left scale, please note the reversed axes) from AVISO for (a) and (b) Ross Sea and (c) and (d) Weddell Sea. The regions are shown by the green boxes in Figure 1a.

\subsection{Long-Term Observed Variability}

We now investigate observational evidence for our model-based findings. Initially we assess if long-term variability is present in the observations. Long consistent data sets are sparse in the Southern Ocean. We use HadISST for SST and sea ice concentration, and SSH from AVISO (i.e., the absolute dynamical height anomaly field). Due to existing caveats and restriction of these data sets, we focus only on the Ross and Weddell Gyre regions (regions selected are highlighted in Figure 1a by the green boxes), where we would expect the clearest signal. Due to seasonal sea ice cover in these regions we take February SSH minimum values to infer the gyre strength indirectly (Figure 9), as was done for the subpolar gyre in the North Atlantic by Böning et al. [2006]. Negative SSH anomalies reflect a strengthening of the gyre circulation and vice versa (see also supporting information Figure S1a and S1b). For the Ross Sea, detrended annual mean sea ice anomalies (grey bars) and February SSH anomalies (red) are shown in Figure 9a. We note that the shortsatellite record prevents us from applying a decadal low-pass filter to the time series. The SSH anomalies (red shading) for the Ross region suggest year to year fluctuations and a subdecadal oscillation, with negative anomalies (strengthening of the gyre) between 1997 and 2003 and an opposite phase around 2005. 
Anomalies are smaller since then and suggest slightly negative SSH anomaly beyond 2010. Sea ice anomalies of about $\pm 200 \times 10^{3} \mathrm{~km}^{2}$ are present over the past 30 years of the record, with large interannual variations.

Focusing just on the period between 1997 and 2007, where the largest long-term signal is present in the SSH record, it appears that most positive sea ice anomalies (grey bars) occur during periods with negative SSH anomalies (red shaded area, increased gyre strength) and vice versa. This anticorrelation agrees with results of the NIWA-UKCA ensemble and a few others models, whereby positive sea ice anomalies correspond to a stronger gyre circulation. The SST anomalies (blue bars) provide some additional evidence for this relationship (Figure 9b). We note a general anticorrelation between sea ice anomalies and SST (comparison between Figures $9 a$ and $9 b$ ). Thus, negative SST anomalies generally coincide with negative SSH anomalies (stronger gyre circulation), which seem to promote positive sea ice anomalies (Figures 9a and 9b). Apart from the 1997-2007 period, no clear long-term (decadal or longer) signal is present either in the SSH or SST/sea ice record. Even during the 1997-2007 period, exceptions from the suggested behavior are present on an annual basis. This leads us to conclude that only for large anomalies is there a small hint of a positive relationship between gyre strength and sea ice anomalies in the Ross Sea region.

For the Weddell Sea region (Figures $9 c$ and 9d), no relationship between gyre strength and SST (as suggested by some model results) is found. Sea ice and SST records show large variations on an annual to interannual basis. The gyre strength (based on the SSH proxy) shows two phases, a predominant negative before 2005 and a positive afterward. Sea ice and SST do not show any evidence for a similar behavior. They also do not show the opposing tendency as one might expect, and as partially seen in the Ross Sea. Based on the outcome of this initial assessment, there is clearly the need for more detailed and longer-term observational records in order to disentangle long-term variability in Ross and Weddell Sea processes, especially with a focus on the subpolar gyre variability.

\section{Discussion and Conclusion}

In this study, we have assessed decadal to multidecadal variability in the Southern Ocean and associated driving mechanisms with respect to subpolar gyre strength, Drake Passage transport, and deep water production, using coupled climate model simulations and observations. In contrast to earlier studies [e.g., Wang, 2013], which based relationships between Southern Ocean quantities on trends, we establish mechanisms for decadal to multidecadal variability. The model results confirm that long-term variability in both Ross and Weddell Gyres, as well as Drake Passage transport and sea ice cover, can be stimulated by open ocean deep convection on various timescales. Having said that, deep convection is either exaggerated or not simulated at all by contemporary climate models [Heuzé et al., 2013; de Lavergne et al., 2014] for reasons such as the representation of the sea ice cover [Turner et al., 2013], SST biases [Wang et al., 2014], and imperfect model parameterizations [Heuzé et al., 2015].

Results from our NIWA-UKCA ensemble show that freshwater perturbations, especially at the surface, are a critical factor in triggering deep convection by influencing the upper ocean stratification in the subpolar Southern Ocean and causing an imbalance of surface fluxes and meridional transports. In the NIWA-UKCA ensemble, the changes in the liquid freshwater content slightly precede changes in the heat content south of $67^{\circ} \mathrm{S}$. This phase shift between liquid freshwater and heat content is partly caused by a larger sea ice export due to both enhanced sea ice production and stronger gyre circulation during nonconvective periods. Expanding sea ice cover reduces the heat fluxes from the ocean to the atmosphere, which leads to a subsurface heat accumulation. The combination of sea ice and associated freshwater export, brine rejection through sea ice formation, and subsurface heat accumulation, weakens the ocean stratification on the longterm. The stored subsurface heat can eventually penetrate the pycnocline, resulting in sea ice melt and its release into the atmosphere while cooler and fresher waters are convectively mixed downward. We recognize the necessity of a slow oceanic response to perturbations for the occurrence of convection. The length and especially the intensity of the convective events are set by the subsurface heat content, in agreement with previous findings by Martin et al. [2013] on centennial time scales. Our results using the NIWA-UKCA ensemble also show that local wind stress curl anomalies have only a limited effect on the gyre dynamics on these long-time scales, which is in agreement to results by Wang and Meredith [2008]. Anomalies associated with open ocean convection are clearly identified as the main driver. This also implies that decadal 
variability of the Antarctic sea ice cover in NIWA-UKCA and other coupled climate models is less affected by local wind stress, while observations suggest a link to sea ice trends [Holland and Kwok, 2012]. This different behavior and potential mismatch may be related to different mechanisms and requires further attention beyond the scope of this study. de Lavergne et al. [2014] concluded that a reoccurrence of open ocean convection (Weddell sea polynya) in the future is unlikely because of an increased surface stratification under global warming. However, our model results suggest that a preconditioning of the ocean (at intermediate depths) can continue under global warming waiting for either favorable surface conditions or building up heat content to overcome the stronger stratification. This highlights the need for further research.

Results from the selected CMIP5 models confirm that such open ocean stimulated variability on decadal to multidecadal timescales is a common feature among coupled climate models. We demonstrated that sea ice cover, Drake Passage transport, and Weddell gyre strength are especially affected by convective variability. Modeled Southern Ocean sea ice cover is known to show larger variability than observations [Zunz et al., 2013], and we find that open ocean convection is a major contributing factor to this bias. As demonstrated by Heuzé et al. [2013], regions and strengths of deep convection in CMIP5 models are largely modeldependent. It is possible that factors other than freshwater anomalies-such as heat flux anomalies, or a combination of both-can trigger these events. In addition, we recognize that the boundary between nonconvective and convective models seems porous, with extremes at both ends. As shown by de Lavergne et al. [2014], deep convection can stop if boundary conditions change. More detailed analysis is required to investigate mechanisms and feedbacks in these models. Our results confirm the findings of Martin et al. [2013] that the sea ice distribution matters for subsurface heat accumulation but in addition highlight the importance of surface freshwater perturbations for driving convective oscillations.

In many coupled climate models, the extent and intensity of modeled open ocean deep convective events is overestimated since there is no observational evidence for similar occurrence in the late 20th and early 21st centuries, apart from a single observed occurrence of the Weddell Sea polynya in 1974-1976 [Carsey, 1980]. The large variability associated with such mixing events in climate models, on the other hand, can be used to more clearly identify associated relationships and feedbacks that otherwise might be masked by other processes. Our results show a large model spread in the CMIP5 ensemble with respect to decadal to multidecadal variability stimulated by convection events. This agrees well with recent studies [Heuzé et al., 2013; Wang, 2013; Meijers, 2014]. Some relationships between Southern Ocean state variables depend on whether a model has open ocean convection or not. We see that in most CMIP5 models positive convective anomalies (i.e., production of dense water) cause positive Drake Passage transport anomalies, irrespective of whether the model has open ocean convection or not. This confirms our understanding that the large scale meridional density gradient is impacted by convection, leading to corresponding changes in the Drake Passage transport [Hirabara et al., 2012; Howard et al., 2015].

It remains unclear why the MPI-LR model does not exhibit this dependency despite showing extensive deep convection in the Weddell Sea [Heuzé et al., 2013; Wang, 2013; de Lavergne et al., 2014] and maintaining exceptionally strong subpolar gyres and large meridional variations in the ACC [Meijers et al., 2012]. More detailed analysis is required to understand this behavior. As a consequence of the positive relation between convection and Drake Passage transport, a relationship between sea ice extent anomalies and Drake Passage transport anomalies can be considered, whereby negative sea ice anomalies are associated with reduced Drake Passage transport. In principle, growing sea ice reduces the likelihood of open ocean convection initially and thus the convection activity is lower. This link is, with the exception of ACCESS13 and NORESM-ME for unknown reasons, present in the selection of CMIP5 models considered in this study. Results of NIWA-UKCA also suggest that persistent sea ice growth can be preconditioning for convection.

For the relationship between sea ice area and Ross Gyre strength, both ensembles show an opposing behavior; a negative relationship for the nonconvective and a positive for the convective models. In contrast, most nonconvective models show a positive connection between sea ice coverage and Weddell Gyre strength anomalies on decadal to multidecadal timescales. They also exhibit a link between Weddell Gyre strength and Drake Passage transport. In open ocean convective models, however, these Weddell Gyre relations seem absent or obscured by the intense local impact of strong convective events in this region.

Observational data products available for this region are limited in their temporal coverage and also restricted mostly to surface variables measurable from space. Neither the Ross nor the Weddell Sea regions 
show clear decadal variability in such data. Records of SSH, sea ice area, and SST exhibit large covariability on shorter-time scales however. The relationship between the subpolar gyre strength and sea ice coverage on decadal timescales suggested by some model results cannot be confirmed. Certainly further work is required, particularly the need for longer observational records to improve our understanding of Southern Ocean variability on interannual to multidecadal timescales.

Based on the presented results in this paper, we conclude:

1. Open ocean deep convection in the Southern Ocean stimulates substantial decadal to multidecadal variability in coupled climate models.

2. Preconditioning of convective events, i.e., increased stratification and subsequent subsurface heat accumulation, is part of a repeating cycle. Internal variability in the surface freshwater forcing and sea ice cover can cause an imbalance in the ocean-atmosphere heat exchange and can be the initial trigger.

3. Most climate models suggest a connection between deep convection, Drake Passage transport (ACC strength) as well as sea ice variability on decadal to multidecadal timescales. Relationships between deep convection and Ross or Weddell Gyre strength are seen but depend on whether models show open ocean convection or not.

\section{Acknowledgments}

We are grateful to both reviewers for their constructive encouragement and persistence in the evolution of our paper. The data which has been used in this manuscript can be made available upon request from the author on a ftp server. We acknowledge the UK MetOffice for use of the MetUM. We acknowledge the contribution of NeSI high-performance computing facilities to the results of this research. NZ's national facilities are provided by the NZ eScience Infrastructure and funded jointly by NeSI's collaborator institutions and through the Ministry of Business, Innovation and Employment's Research Infrastructure programme (https://www.nesi.org.nz). This work has been supported by NIWA as part of its Government-funded, core research, the Deep South National Science Challenge, and by the Marsden Fund Council from Government funding, administered by the Royal Society of New Zealand (grant 12-NIW-006). We also thank colleagues of the UNSW in Sydney for their support and constructive discussions. The altimeter products were produced by Ssalto/Duacs and distributed by Aviso, with support from Cnes (http://www.aviso.altimetry.fr/ duacs/). The authors wish to acknowledge use of the Ferret program for analysis and graphics in this paper. Ferret is a product of NOAA's Pacific Marine Environmental Laboratory. (Information is available at http://ferret.pmel.noaa.gov/Ferret/). We also thank Helen Macdonald for additional constructive comments.

\section{References}

Behrens, E. (2013), The oceanic response to Greenland melting: The effect of increasing model resolution. University library of the Christian-Albrechts-University of Kiel, Germany. [Availble at http://macau.uni-kiel.de/receive/dissertation_diss_00013684.]

Best, M. J. et al. (2011), The Joint UK Land Environment Simulator (JULES), model description: Part 1: Energy and water fluxes, Geosci. Model Dev., 4(3), 677-699, doi:10.5194/gmd-4-677-2011.

Bintanja, R., G. J. van Oldenborgh, S. S. Drijfhout, B. Wouters, and C. A. Katsman (2013), Important role for ocean warming and increased ice-shelf melt in Antarctic sea-ice expansion, Nat. Geosci., 6(5), 376-379, doi:10.1038/ngeo1767.

Böning, C. W., M. Scheinert, J. Dengg, A. Biastoch, and A. Funk (2006), Decadal variability of subpolar gyre transport and its reverberation in the North Atlantic overturning, Geophys. Res. Lett., 33, L21S01, doi:10.1029/2006GL026906.

Böning, C. W., A. Dispert, M. Visbeck, S. R. Rintoul, and F. U. Schwarzkopf (2008), The response of the Antarctic Circumpolar Current to recent climate change, Nat. Geosci., 1(12), 864-869, doi:10.1038/ngeo362.

Carsey, F. D. (1980), Microwave observation of the Weddell Polynya, Mon. Weather Rev., 108(12), 2032-2044, doi:10.1175/15200493(1980) $108<2032:$ MOOTWP $>2.0 . C O ; 2$.

Clark, D. B. et al. (2011), The Joint UK Land Environment Simulator (JULES), model description: Part 2: Carbon fluxes and vegetation dynamics, Geosci. Model Dev., 4(3), 701-722, doi:10.5194/gmd-4-701-2011.

Cunningham, S. A., S. G. Alderson, B. A. King, and M. A. Brandon (2003), Transport and variability of the Antarctic Circumpolar Current in Drake Passage, J. Geophys. Res., 108(C5), 8084, doi:10.1029/2001JC001147.

de Lavergne, C., J. B. Palter, E. D. Galbraith, R. Bernardello, and I. Marinov (2014), Cessation of deep convection in the open Southern Ocean under anthropogenic climate change, Nat. Clim. Change, 4(4), 278-282, doi:10.1038/nclimate2132.

Downes, S. M., and A. M. C. C. Hogg (2013), Southern Ocean Circulation and Eddy Compensation in CMIP5 Models, J. Clim., 26(18), 71987220, doi:10.1175/JCLI-D-12-00504.1.

Downes, S. M., et al. (2015), An assessment of Southern Ocean water masses and sea ice during 1988-2007 in a suite of inter-annual COREII simulations, Ocean Modell., 94, 67-94, doi:10.1016/j.ocemod.2015.07.022.

Eyring, V., J.-F. Lamarque, P. Hess, F. Arfeuille, K. Bowman, M. P. Chipperfiel, B. Duncan, A. Fiore, A. Gettelman, and M. A. Giorgetta (2013), Overview of IGAC/SPARC Chemistry-Climate Model Initiative (CCMI) community simulations in support of upcoming ozone and climate assessments, Sparc Newsl., 40(Januar), 48-66, SPARC Newsletter No. 40, pp. 48-66.

Fahrbach, E., G. Rohardt, N. Scheele, M. Schröder, V. Strass, and A. Wisotzki (1995), Formation and discharge of deep and bottom water in the northwestern Weddell Sea, J. Mar. Res., 53(4), 515-538, doi:10.1357/0022240953213089.

Farneti, R., T. L. Delworth, A. J. Rosati, S. M. Griffies, and F. Zeng (2010), The role of mesoscale eddies in the rectification of the Southern Ocean response to climate change, J. Phys. Oceanogr., 40(7), 1539-1557, doi:10.1175/2010JPO4353.1.

Farneti, R., et al. (2015), An assessment of Antarctic Circumpolar Current and Southern Ocean Meridional Overturning Circulation during 1958-2007 in a suite of interannual CORE-II simulations, Ocean Modell., 93, 84-120, doi:10.1016/j.ocemod.2015.07.009.

Gent, P. R., and J. C. Mcwilliams (1990), Isopycnal mixing in ocean circulation models, J. Phys. Oceanogr., 20(1), 150-155, doi:10.1175/15200485(1990)020<0150:IMIOCM > 2.0.CO;2.

Goosse, H., and V. Zunz (2014), Decadal trends in the Antarctic sea ice extent ultimately controlled by ice-ocean feedback, Cryosphere, 8(2), 453-470, doi:10.5194/tc-8-453-2014.

Heuzé, C., K. J. Heywood, D. P. Stevens, and J. K. Ridley (2013), Southern Ocean bottom water characteristics in CMIP5 models, Geophys. Res. Lett., 40, 1409-1414, doi:10.1002/grl.50287.

Heuzé, C., J. K. Ridley, D. Calvert, D. P. Stevens, and K. J. Heywood (2015), Increasing vertical mixing to reduce Southern Ocean deep convection in NEMO3.4, Geosci. Model Dev., 8(10), 3119-3130, doi:10.5194/gmd-8-3119-2015.

Hewitt, H. T., D. Copsey, I. D. Culverwell, C. M. Harris, R. S. R. Hill, A. B. Keen, A. J. McLaren, and E. C. Hunke (2011), Design and implementation of the infrastructure of HadGEM3: The next-generation Met Office climate modelling system, Geosci. Model Dev., 4(2), 223-253, doi: 10.5194/gmd-4-223-2011.

Hirabara, M., H. Tsujino, H. Nakano, and G. Yamanaka (2012), Formation mechanism of the Weddell Sea Polynya and the impact on the global abyssal ocean, J. Oceanogr., 68(5), 771-796, doi:10.1007/s10872-012-0139-3.

Hogg, A. M., M. P. Meredith, D. P. Chambers, E. P. Abrahamsen, C. W. Hughes, and A. K. Morrison (2013), Recent trends in the Southern Ocean eddy field, J. Geophys. Res. Oceans, 120, 257-267, doi:10.1002/2014JC010470.

Holland, P. R., and R. Kwok (2012), Wind-driven trends in Antarctic sea-ice drift, Nat. Geosci., 5(12), 872-875, doi:10.1038/ngeo1627. 
Howard, E., A. McC. Hogg, S. Waterman, and D. P. Marshall (2015), The injection of zonal momentum by buoyancy forcing in a Southern Ocean model, J. Phys. Oceanogr., 45(1), 259-271, doi:10.1175/JPO-D-14-0098.1.

Hunke, E., and W. Lipscomb (2010), CICE: The Los Alamos Sea Ice Model, Documentation and Software User's Manual, version 4.1, LA-CC06-012.

Jacobs, S. S., and J. C. Comiso (1989), Sea ice and oceanic processes on the Ross Sea continental shelf, J. Geophys. Res., 94(C12), 18,19518,211, doi:10.1029/JC094iC12p18195.

Latif, M., T. Martin, and W. Park (2013), Southern Ocean Sector Centennial Climate Variability and Recent Decadal Trends, J. Clim., 26(19), 7767-7782, doi:10.1175/JCLI-D-12-00281.1.

Madec, G. (2008), NEMO the Ocean Engine, Tech. Rep., Notes de I'IPSL, 27, 193 pp.

Martin, S., R. S. Drucker, and R. Kwok (2007), The areas and ice production of the western and central Ross Sea polynyas, 1992-2002, and their relation to the B-15 and C-19 iceberg events of 2000 and 2002, J. Mar. Syst., 68(1-2), 201-214, doi:10.1016/j.jmarsys.2006.11.008.

Martin, T., W. Park, and M. Latif (2013), Multi-centennial variability controlled by Southern Ocean convection in the Kiel Climate Model, Clim. Dyn., 40(7-8), 2005-2022, doi:10.1007/s00382-012-1586-7.

Martin, T., W. Park, and M. Latif (2015), Southern Ocean forcing of the North Atlantic at multi-centennial time scales in the Kiel Climate Model, Deep Res., Part II, Top. Stud. Oceanogr., 114, 39-48, doi:10.1016/j.dsr2.2014.01.018.

Mazloff, M. R., P. Heimbach, and C. Wunsch (2010), An Eddy-permitting southern ocean state estimate, J. Phys. Oceanogr., 40(5), 880-899, doi:10.1175/2009JPO4236.1.

Meijers, A. J. S. (2014), The Southern Ocean in the coupled model intercomparison project phase 5, Philos. Trans. R. Soc. A., 372(2019), 20130296, doi:10.1098/rsta.2013.0296.

Meijers, A. J. S., E. Shuckburgh, N. Bruneau, J.-B. Sallee, T. J. Bracegirdle, and Z. Wang (2012), Representation of the Antarctic Circumpolar Current in the CMIP5 climate models and future changes under warming scenarios, J. Geophys. Res., 117, C12008, doi:10.1029/ $2012 J C 008412$.

Meinshausen, M. et al. (2011), The RCP greenhouse gas concentrations and their extensions from 1765 to 2300, Clim. Change, 109(1-2), 213-241, doi:10.1007/s10584-011-0156-z.

Meredith, M. P., A. C. Naveira Garabato, A. M. Hogg, and R. Farneti (2012), Sensitivity of the overturning circulation in the southern ocean to decadal changes in wind forcing, J. Clim., 25(1), 99-110, doi:10.1175/2011JCLI4204.1.

Morgenstern, O., G. Zeng, S. M. Dean, M. Joshi, N. L. Abraham, and A. Osprey (2014), Direct and ozone-mediated forcing of the Southern Annular Mode by greenhouse gases, Geophys. Res. Lett., 41, 9050-9057, doi:10.1002/2014GL062140.

Polvani, L. M., and K. L. Smith (2013), Can natural variability explain observed Antarctic sea ice trends? New modeling evidence from CMIP5, Geophys. Res. Lett., 40, 3195-3199, doi:10.1002/grl.50578.

Purkey, S. G., and G. C. Johnson (2013), Antarctic bottom water warming and freshening: Contributions to sea level rise, ocean freshwater budgets, and global heat gain*, J. Clim., 26(16), 6105-6122, doi:10.1175/JCLI-D-12-00834.1.

Rayner, N. A. (2003), Global analyses of sea surface temperature, sea ice, and night marine air temperature since the late nineteenth century, J. Geophys. Res., 108(D14), 4407, doi:10.1029/2002JD002670.

Rickard, G. J., M. J. Roberts, M. J. M. Williams, A. Dunn, and M. H. Smith (2010), Mean circulation and hydrography in the Ross Sea sector, Southern Ocean: Representation in numerical models, Antarct. Sci., 22(5), 533-558, doi:10.1017/S0954102010000246.

Rintoul, S. R., and A. C. N. Garabato (2013), Dynamics of the Southern Ocean Circulation, Ocean Circ. Clim. A 21st Century Perspect., 103, 471492, doi:10.1016/B978-0-12-391851-2.00018-0.

Rintoul, S. R. (2007), Rapid freshening of Antarctic Bottom Water formed in the Indian and Pacific oceans, Geophys. Res. Lett., 34, L06606, doi:10.1029/2006GL028550.

Sallée, J.-B., E. Shuckburgh, N. Bruneau, A. J. S. Meijers, T. J. Bracegirdle, and Z. Wang (2013), Assessment of Southern Ocean mixed-layer depths in CMIP5 models: Historical bias and forcing response, J. Geophys. Res. Oceans, 118, 1845-1862, doi:10.1002/jgrc.20157.

Sokolov, S., and S. R. Rintoul (2009), Circumpolar structure and distribution of the Antarctic Circumpolar Current fronts: 1. Mean circumpolar paths, J. Geophys. Res., 114, C11018, doi:10.1029/2008JC005108.

Spence, P., S. M. Griffies, M. H. England, A. M. Hogg, O. a. Saenko, and N. C. Jourdain (2014), Rapid subsurface warming and circulation changes of Antarctic coastal waters by poleward shifting winds, Geophys. Res. Lett., 41, 4601-4610, doi:10.1002/2014GL060613.

Stössel, A., D. Notz, F. A. Haumann, H. Haak, J. Jungclaus, and U. Mikolajewicz (2014), Controlling high-latitude Southern Ocean convection in climate models, Ocean Modell., 86, 58-75, doi:10.1016/j.ocemod.2014.11.008.

Turner, J., T. J. Bracegirdle, T. Phillips, G. J. Marshall, and J. S. Hosking (2013), An initial assessment of Antarctic Sea ice extent in the CMIP5 models, J. Clim., 26(5), 1473-1484, doi:10.1175/JCLI-D-12-00068.1.

Wang, C., L. Zhang, S.-K. Lee, L. Wu, and C. R. Mechoso (2014), A global perspective on CMIP5 climate model biases, Nat. Clim. Change, 4(3), 201-205, doi:10.1038/nclimate2118.

Wang, Z. (2013), On the response of Southern Hemisphere subpolar gyres to climate change in coupled climate models, J. Geophys. Res. Oceans, 118, 1070-1086, doi:10.1002/jgrc.20111.

Wang, Z., and M. P. Meredith (2008), Density-driven Southern Hemisphere subpolar gyres in coupled climate models, Geophys. Res. Lett., 35, L14608, doi:10.1029/2008GL034344.

WMO (2011), World Meteorological Organization: Scientific Assessment of Ozone Depletion: 2010, World Meteorological Organization Global Ozone Research and Monitoring Project - Report No 52, Geneva, Switzerland.

Zunz, V., H. Goosse, and F. Massonnet (2013), How does internal variability influence the ability of CMIP5 models to reproduce the recent trend in Southern Ocean sea ice extent?, Cryosphere, 7(2), 451-468, doi:10.5194/tc-7-451-2013. 